OPEN ACCESS

Edited by:

Urs Granacher,

University of Potsdam, Germany

Reviewed by:

Helmi Chaabene,

University of Potsdam, Germany

David George Behm,

Memorial University of Newfoundland,

Canada

František Zahálka

Charles University, Czechia

${ }^{*}$ Correspondence:

Erika Zemkova

erika.zemkova@uniba.sk

Specialty section:

This article was submitted to

Exercise Physiology,

a section of the journal

Frontiers in Physiology

Received: 29 September 2017 Accepted: 08 March 2018

Published: 11 April 2018

Citation:

Zemková E and Hamar D (2018) Sport-Specific Assessment of the

Effectiveness of Neuromuscular

Training in Young Athletes.

Front. Physiol. 9:264

doi: 10.3389/fphys.2018.00264

\section{Sport-Specific Assessment of the Effectiveness of Neuromuscular Training in Young Athletes}

\author{
Erika Zemková $^{1,2 *}$ and Dušan Hamar ${ }^{1}$ \\ ${ }^{1}$ Department of Sports Kinanthropology, Faculty of Physical Education and Sport, Comenius University in Bratislava, \\ Bratislava, Slovakia, ${ }^{2}$ Sports Technology Institute, Faculty of Electrical Engineering and Information Technology, Slovak \\ University of Technology in Bratislava, Bratislava, Slovakia
}

Neuromuscular training in young athletes improves performance and decreases the risk of injuries during sports activities. These effects are primarily ascribed to the enhancement of muscle strength and power but also balance, speed and agility. However, most studies have failed to demonstrate significant improvement in these abilities. This is probably due to the fact that traditional tests do not reflect training methods (e.g., plyometric training vs. isometric or isokinetic strength testing, dynamic balance training vs. static balance testing). The protocols utilized in laboratories only partially fulfill the current needs for testing under sport-specific conditions. Moreover, laboratory testing usually requires skilled staff and a well equipped and costly infrastructure. Nevertheless, experience demonstrates that high-technology and expensive testing is not the only way to proceed. A number of physical fitness field tests are available today. However, the low reliability and limited number of parameters retrieved from simple equipment used also limit their application in competitive sports. Thus, there is a need to develop and validate a functional assessment platform based on portable computerized systems. Variables obtained should be directly linked to specific features of particular sports and capture their complexity. This is essential for revealing weak and strong components of athlete performance and design of individually-tailored exercise programs. Therefore, identifying the drawbacks associated with the assessment of athlete performance under sport-specific conditions would provide a basis for the formation of an innovative approach to their long-term systematic testing. This study aims (i) to review the testing methods used for the evaluation of the effect of neuromuscular training on sport-specific performance in young athletes, (ii) to introduce stages within the Sport Longlife Diagnostic Model, and (iii) to propose future research in this topic. Analysis of the literature identified gaps in the current standard testing methods in terms of their low sensitivity in discriminating between athletes of varied ages and performance levels, insufficent tailoring to athlete performance level and individual needs, a lack of specificity to the requirements of particular sports and also in revealing the effect of training. In order to partly fill in these gaps, the Sport Longlife Diagnostic Model was proposed.

Keywords: agility, balance, core stability, muscle strength and power, speed, testing 


\section{INTRODUCTION}

All of us are aware of the importance of reaching the correct diagnosis to identify the illness and craft a prompt treatment. Though sport cannot be compared with clinics, the right and accurate assessment of athlete performance is crucial for designing effective training programs. Getting the right diagnostics is also a key for physical fitness development in general population. It provides useful information on their strengths and weakness and in this way it may reveal potential health risks. By focusing exercise programs on these aspects, it may prevent some type of diseases or injuries before they ever occur.

So far, most of the diseases have been linked to the elderly population; however today, more than ever before they affect middle-aged people (e.g., low back pain), and even the young generation (e.g., diabetes). This issue could be related to workplace conditions (occupational stress, manual operations, etc.) and/or a sedentary way of life. Identifying symptoms associated with a particular disease by assessing the body balance, muscle strength and power or hamstring flexibility may be considered as a "preventive" tool before it starts to become a chronic disease.

Although several field tests have been proposed for various populations, most of them do not meet the requirements of the modern age. One of their main shortcomings is the insufficient reliability and limited number of variables due to the very simple equipment used. Therefore, there is a need to apply portable computerized systems for testing both athletes and untrained subjects of different ages and fitness levels. Only on the basis of relevant variables, their performance capabilities may be evaluated and appropriate exercise programs designed. Testing batteries should include user-friendly, portable and low-cost diagnostic systems well suited for the testing of varied groups in a relatively short time period. These batteries might be applicable in clinical settings, as well as in non-medical institutions, fitness centers or school sports clubs.

In particular, testing batteries for young individuals should get a makeover. So far, a variety of them have been developed for school age children. In Europe, it is the Eurofit Physical Fitness Test Battery, devised by the Council of Europe, that has been used in many European schools since 1988. This test battery includes nine tests assessing speed, strength, endurance and flexibility. Despite the many advantages of field tests, these do not sufficiently reflect various aspects of physical fitness relevant to a particular age and are not sensitive enough to exercise induced changes specific to a particular sport. These traditional methods of assessing the physical fitness of children and adolescents only partially fulfill current needs for testing under sport-specific conditions.

Preliminary analysis of the literature identified the gap in current standard testing methods in terms of their low sensitivity in discriminating between young athletes of varied ages and performance levels and specificity to reveal the effect of training. This study aims (i) to review the existing testing methods used for the evaluation of the effect of neuromuscular training on sport-specific performance in young athletes, (ii) to introduce stages within the Sport Longlife Diagnostic Model, and (iii) to propose future research in this topic.

\section{METHODS}

Two specific questions were addressed in this review: (1) Can existing testing methods effectively evaluate changes in sportspecific performance of young athletes following neuromuscular training? and (2) Which of the current tests are suitable to be implemented in the Sport Longlife Diagnostic Model?

In order to answer these questions and to reveal the gaps in the current literature, we provided a literature search. Electronically available literature was searched using the MEDLINE database, PubMed, SportDiscus ${ }^{\circledR}$ and Web of Science. Additional searches were performed on SpringerLink, Elsevier, EBSCOhost and Google Scholar. Besides peer-reviewed journal articles, available conference proceedings were analyzed. Search results were limited to studies closely related to the main topic of this reviewto identify methods used for assessment of the effectiveness of neuromuscular training on physical fitness in children and adolescents. Our primary focus was on testing under sportspecific conditions. However, this approach resulted in the identification of a small number of studies that were considered eligible for the review. Therefore other relevant studies that evaluated the effect of training on at least one measure of neuromuscular functions and/or athletic performance were included. This help us to identify the gap in current testing methods using for evaluation of changes in neuromuscular performance after specific training in a particular sport.

The target population was young competitive athletes coupled with other groups of children and adolescents involved in physical activities in sport clubs or schools. The most frequent terms "neuromuscular training," "resistance training," "strength and power training," "plyometric training," "muscular fitness," "muscle strength," "muscle power," and "muscular endurance" used for research procedure were combined with particular sports (basketball, gymnastics, soccer, swimming, tennis, volleyball, etc.). Further searches were conducted using relevant words from each subheading, namely tests used for assessment of muscular fitness. The key inclusion criterion was that studies evaluated the effects of neuromuscular training on sport-specific athlete performance. In consequence of limited research in this field, studies investigating the effects of such a training on traditional measures of muscle strength and power, core stability and strength, body balance, agility and speed were also included. These abilities represent a crucial aspect of performance in many sports, and therefore their assessment should be an integral part of testing in young athletes. Studies were excluded if tests or testing batteries were not sufficiently specified. Studies that failed to meet these conditions were excluded from this review. 


\section{RESULTS AND DISCUSSION}

\section{Overview of Test Batteries for Assessment of Physical Fitness in Children and Adolescents}

Fitness testing is a common part of the curriculum in many schools. These testing programs vary across regions, countries and continents.

One of the first were the American Alliance for Health, Physical Education, Recreation and Dance (AAHPERD) test battery, developed in 1957, which included pull-up, standing long jump, flexed leg sit-up, shuttle run, 50-yard dash, and 600-yard run (option: 1 mile or 9 min run for 10-12 years old, and 1.5 miles or 12 min run for $\geq 13$ years old) (AAHPERD, 1976), and the Canadian Association for Health, Physical Education and Recreation (CAHPER) test battery, which dates back to 1963, and included flexed arm hang, standing long jump, 1 min speed situps, shuttle run, $50 \mathrm{~m}$ run and endurance run ( $800 \mathrm{~m}$ run for 6-9 years old, 1,600 m run for 10-12 years old, and 2,400 $\mathrm{m}$ run for 13-17 years old) (CAHPER, 1980).

In 1994, AAHPERD adopted FITNESSGRAM as its national fitness testing program. The FITNESSGRAM Health-related fitness test battery consists of following tests: bent arm hang (included in 1987), pull up (included in 1987, removed in 2005), $90^{\circ}$ push-up (included in 1992), modified pull up (included in 1992), curl-up (included in 1992), trunk lift (included in 1992), modified sit-up test (included in 1987, removed in 1992), one mile run/walk (included in 1987), one mile walk test (included in 1999), PACER test-a $20 \mathrm{~m}$ progressive, multi-stage shuttle run (included in 1992), shuttle run K-3 (included in 1987, removed in 1992), sit and reach test (included in 1987, removed in 1992), shoulder stretch (included in 1992), and back saver sit and reach (included in 1992; Plowman et al., 2006).

However, in September 2012 the New Presidential Youth Fitness Program was launched. This program is focused on assessing health rather than the athleticism of America's youth. The updated version was intended to assess health related fitness of youth with emphasis on their personal goals. This new program was developed in partnership with experts in youth fitness and health promotion including the Amateur Athletic Union, the American Alliance for Health, Physical Education, Recreation and Dance, the Centers for Disease Control and Prevention and the Cooper Institute.

In Europe, the most used is the Eurofit Physical Fitness Test Battery (Council of Europe, Committee for the Development of Sport, 1993) that includes plate tapping-tests speed of limb movement, handgrip test-measures static arm strength, bent arm hang-measures muscular endurance/functional strength, standing broad jump-measures explosive leg power, sit-ups in $30 \mathrm{~s}$-measures trunk strength, $10 \times 5 \mathrm{~m}$ shuttle run-measures running speed and agility, $20 \mathrm{~m}$ endurance shuttle run-tests cardiorespiratory endurance, flamingo balance test-single leg balance test, and sit-and-reach-flexibility test. Another example is the Assessing Levels of Physical Activity (ALPHA) healthrelated fitness test battery for children and adolescents. This includes a $20 \mathrm{~m}$ shuttle run test, handgrip strength test, standing broad jump, and a $4 \times 10 \mathrm{~m}$ shuttle run test (Ruiz et al., 2011).
Further examples are: International Physical Fitness Test (United States Sports Academic, General Organization of Youth and Sport of Bahrain), Amateur Athletic Union Test Battery (Chrysler Foundation, Amateur Athletic Union), YMCA Youth Fitness Test, National Youth Physical Program (the United States Marines Youth Foundation), Fit-4-Fun test battery, Canadian Physical Activity, Fitness and Lifestyle Approach (Canadian Society for Exercise Physiology), National Fitness Test Program in the Popular Republic China (China's National Sport and Physical Education Committee), Australian Fitness Education Award (the Australian Council for Health, Education and Recreation), New Zealand Fitness Test (Rusell, Department of Education), and so forth.

In general, these batteries include tests assessing endurance (e.g., $20 \mathrm{~m}$ shuttle run, Cooper test $-12 \mathrm{~min}$ run, $9 \mathrm{~min}$ run, cycle ergometer sub-maximal test, 1.5 mile run/walk test, 1 mile run/walk test, $1 / 2$ mile run/walk test, $1 / 4$ mile run/walk test, $1,000 \mathrm{~m}$ run), speed and agility (e.g., $50 \mathrm{~m}$ sprint or 50 yard run, $100 \mathrm{~m}$ dash, shuttle run for $4 \times 10 \mathrm{~m}$ or $10 \times 5 \mathrm{~m}$, shuttle run with sponges for $10 \times 4 \mathrm{~m}$, plate tapping), muscle strength (e.g., handgrip, medicine ball or basketball throw, bent arm hang, push-ups and their modifications, standing broad jump, vertical jump-countermovement jump, Abalakov jump and Sargent jump-vertical jump tests with the arms swing, sit-ups and their modifications-7-stage, 30, $60 \mathrm{~s}$, or up to failure, trunk lift), balance (e.g., Flamingo balance test), and flexibility (e.g., sit and reach, stand and reach, $\mathrm{V}$ sit and reach, and shoulder stretch).

Similar test batteries consisting primarily of strength tests have been used to evaluate the effect of neuromuscular training on physical fitness in children and adolescents (Table 1). These batteries include mainly repetition maximum (1, 6, $10 \mathrm{RM}$ ) strength test on various exercises (e.g., bench press, squat, leg press, knee extension, elbow flexion), isometric strength tests (e.g., leg extensors on a leg press), medicine ball throwing, push-ups, curl-ups, handgrip, repeated leg press or chest press exercise, standing long jump, vertical jump (e.g., squat jump, countermovement jump, drop jump, jumping sideways, triple hop, single-leg hop, maximal and submaximal hopping), Bourban trunk muscle strength test-assesses core strength endurance, speed and agility tests (sprints at 10, 20 , or $30 \mathrm{~m}$, shuttle run, Illinois agility test), PACER testmultistage, $20 \mathrm{~m}$ shuttle run, half mile run, one mile run, or other cardiorespiratory fitness tests, static and dynamic balance tests (e.g., standing on a stable platform or those exposed to perturbations, Stork stand balance test, Y balance test, Star excursion balance test), flexibility tests (stand and reach, sit and reach, $\mathrm{V}$ sit and reach, shoulder stretch), and other more specific tests based for instance, on coordination tasks.

\section{Overview of Tests for Assessment of the Effect of Neuromuscular Training on Athlete Performance}

Analysis of the literature identified (Table 1) that the efficiency of neuromuscular training (namely resistance and plyometric or in combination with balance, agility and other exercises) was evaluated mainly by repetition maximum tests $(1,3,6$, 


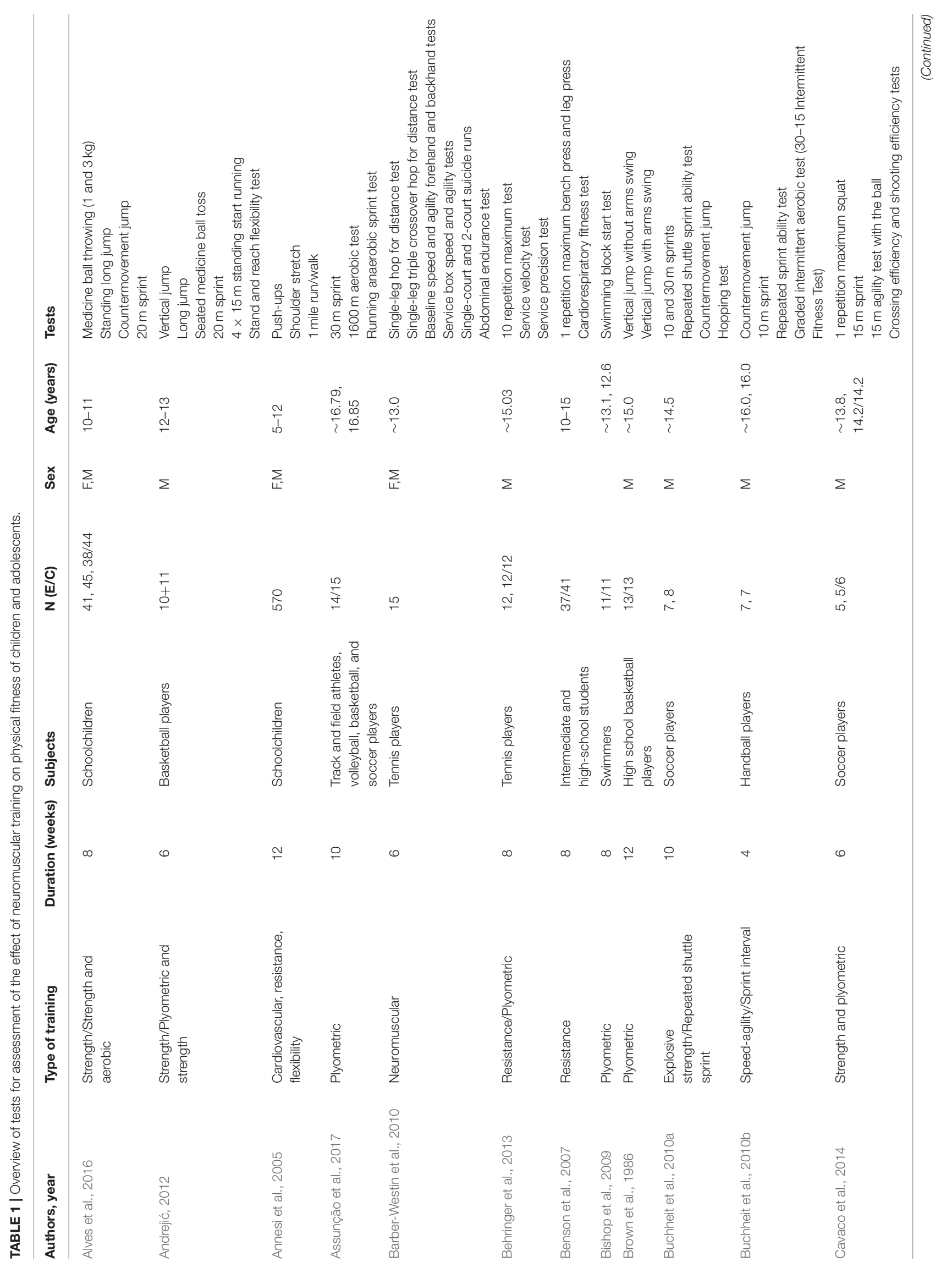




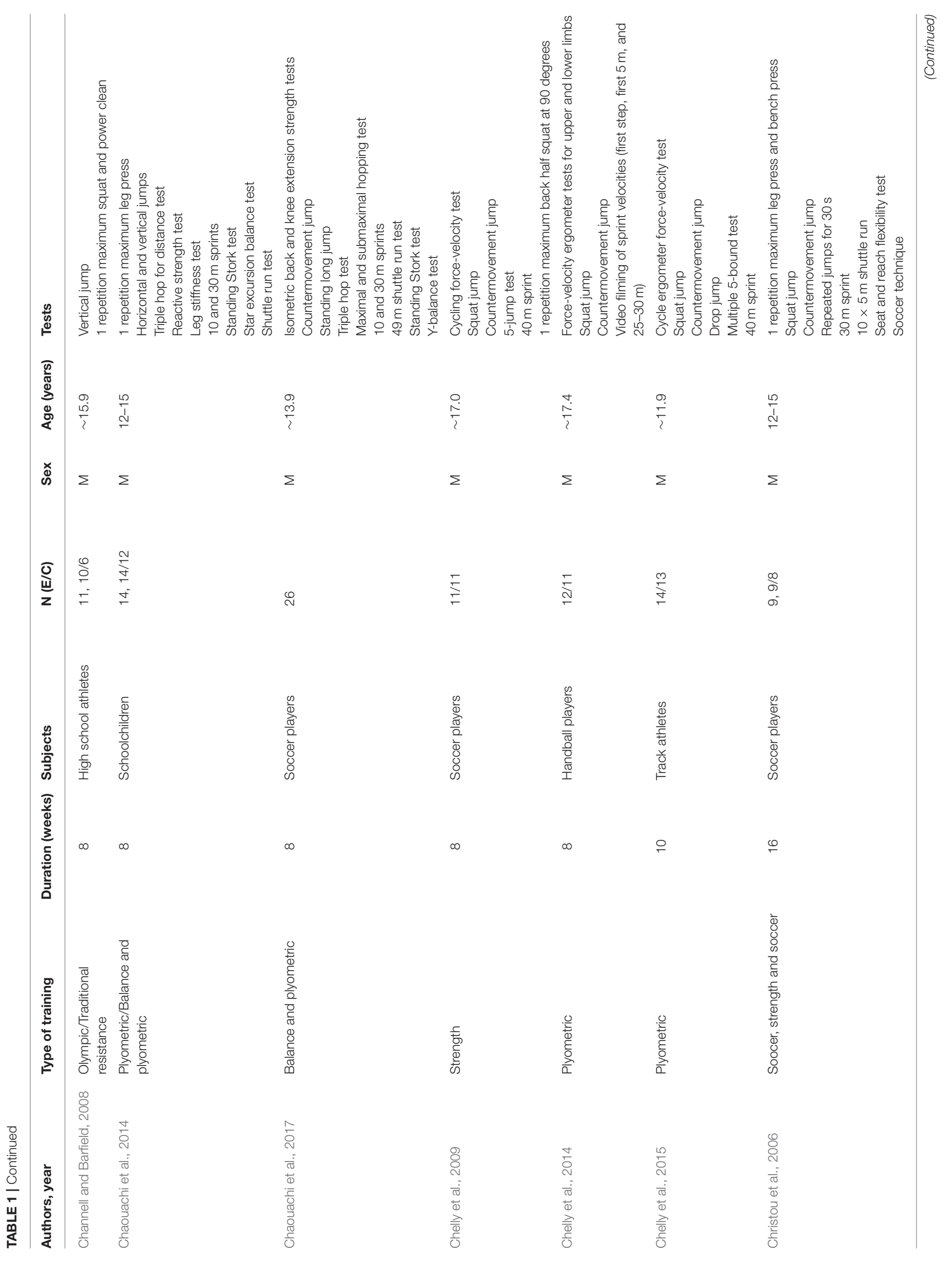


Zemková and Harar

Sport-Specific Assessment of Young Athletes

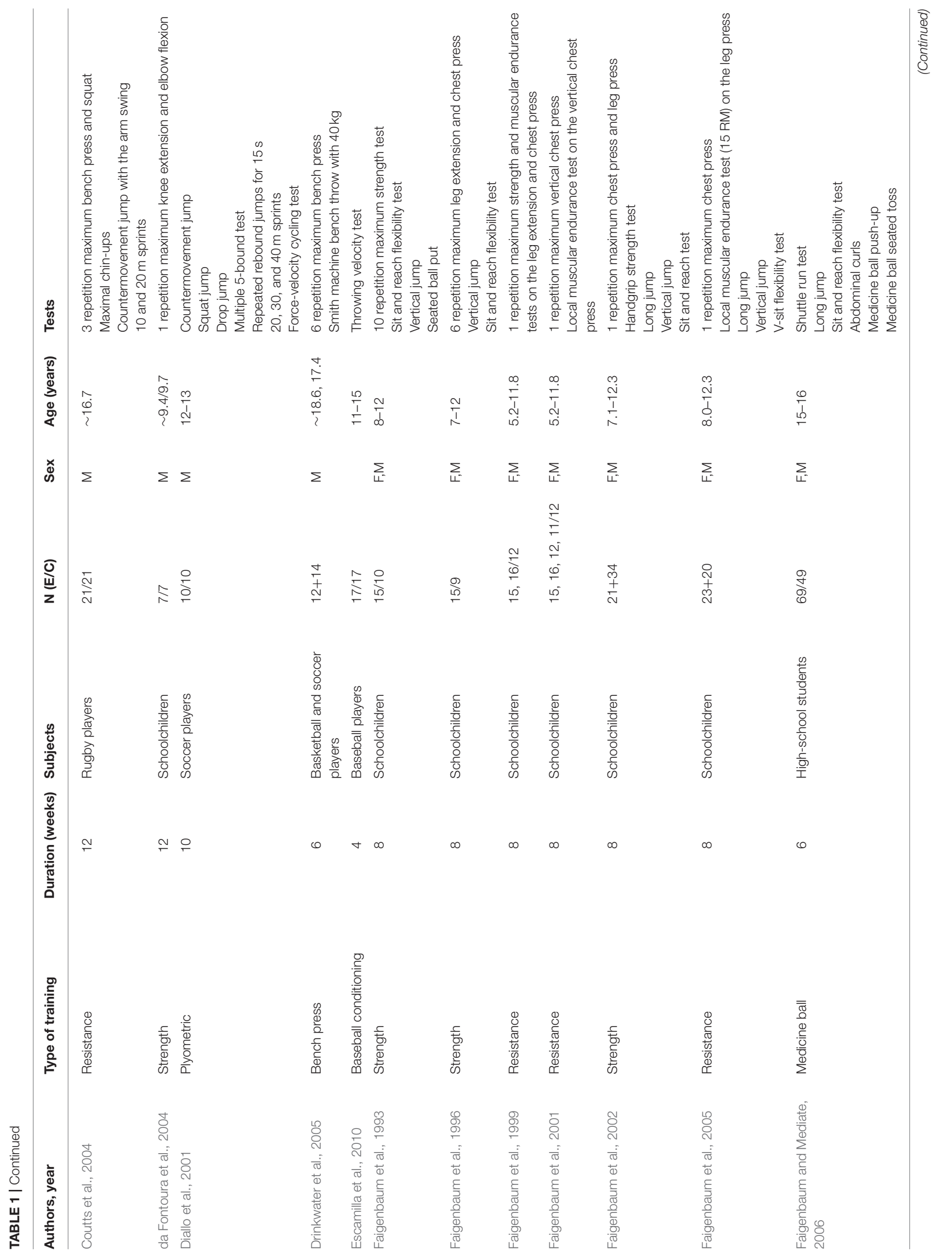

Frontiers in Physiology | www.frontiersin.org

6

April 2018 | Volume 9 | Article 264 


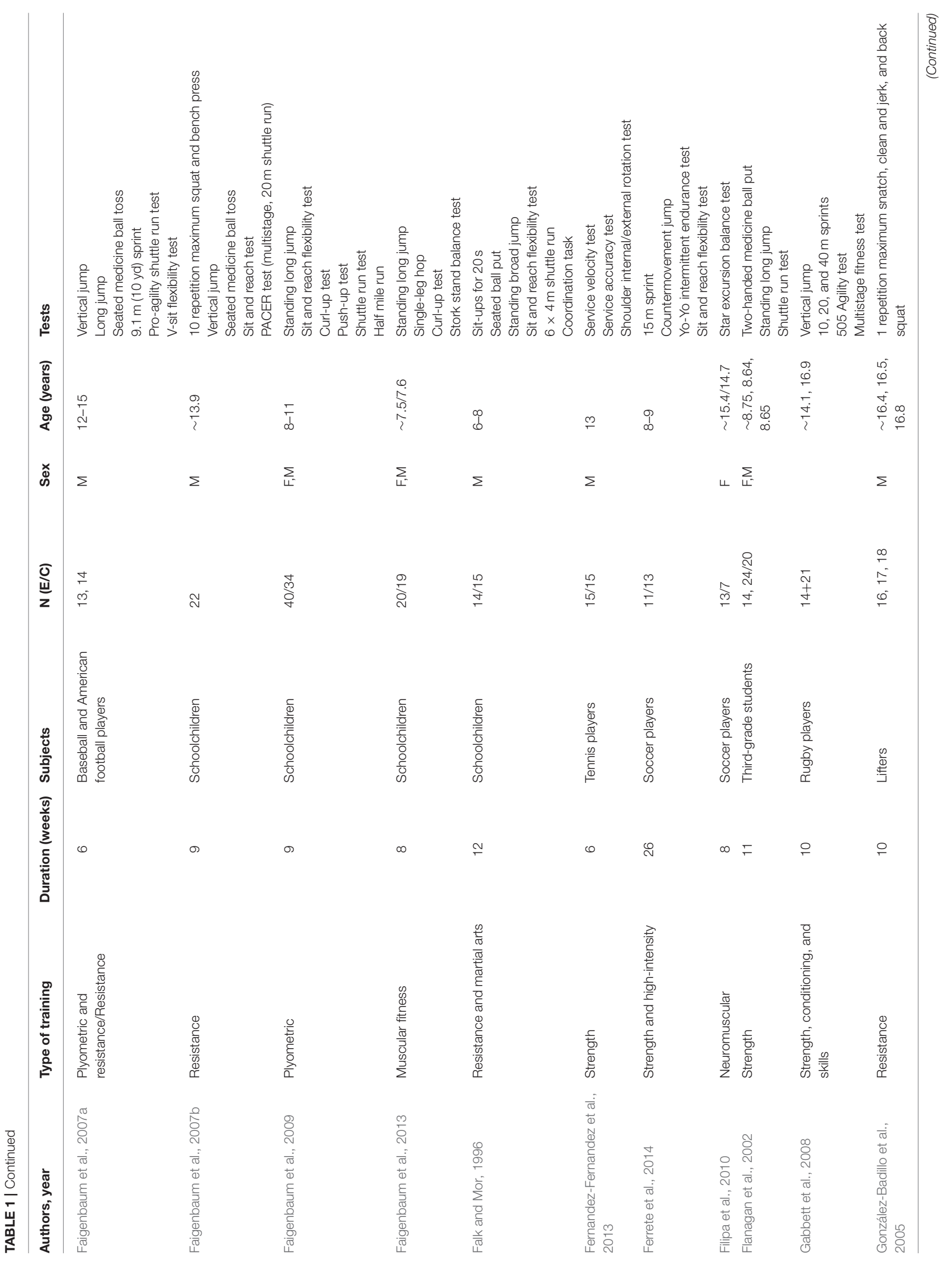




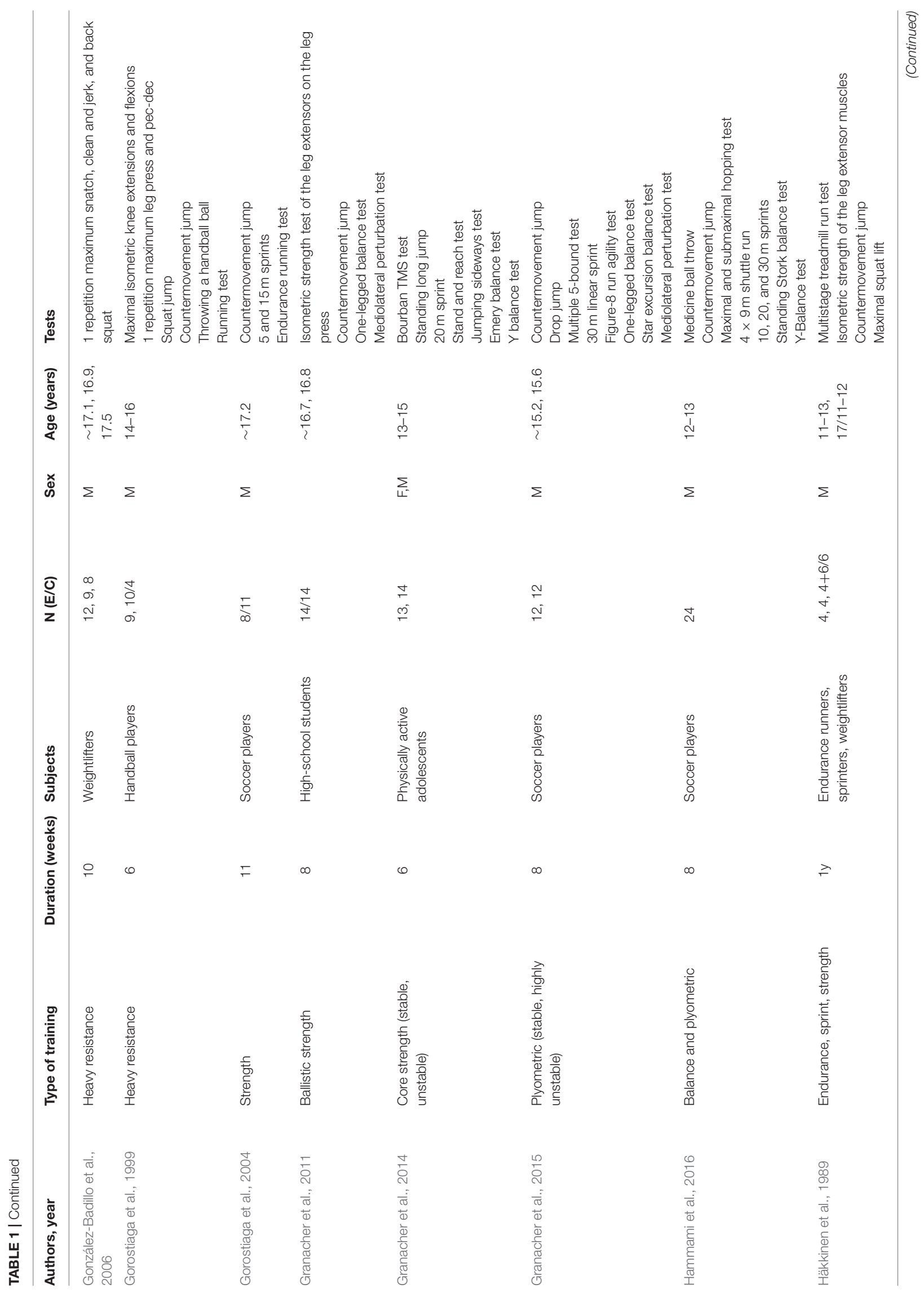




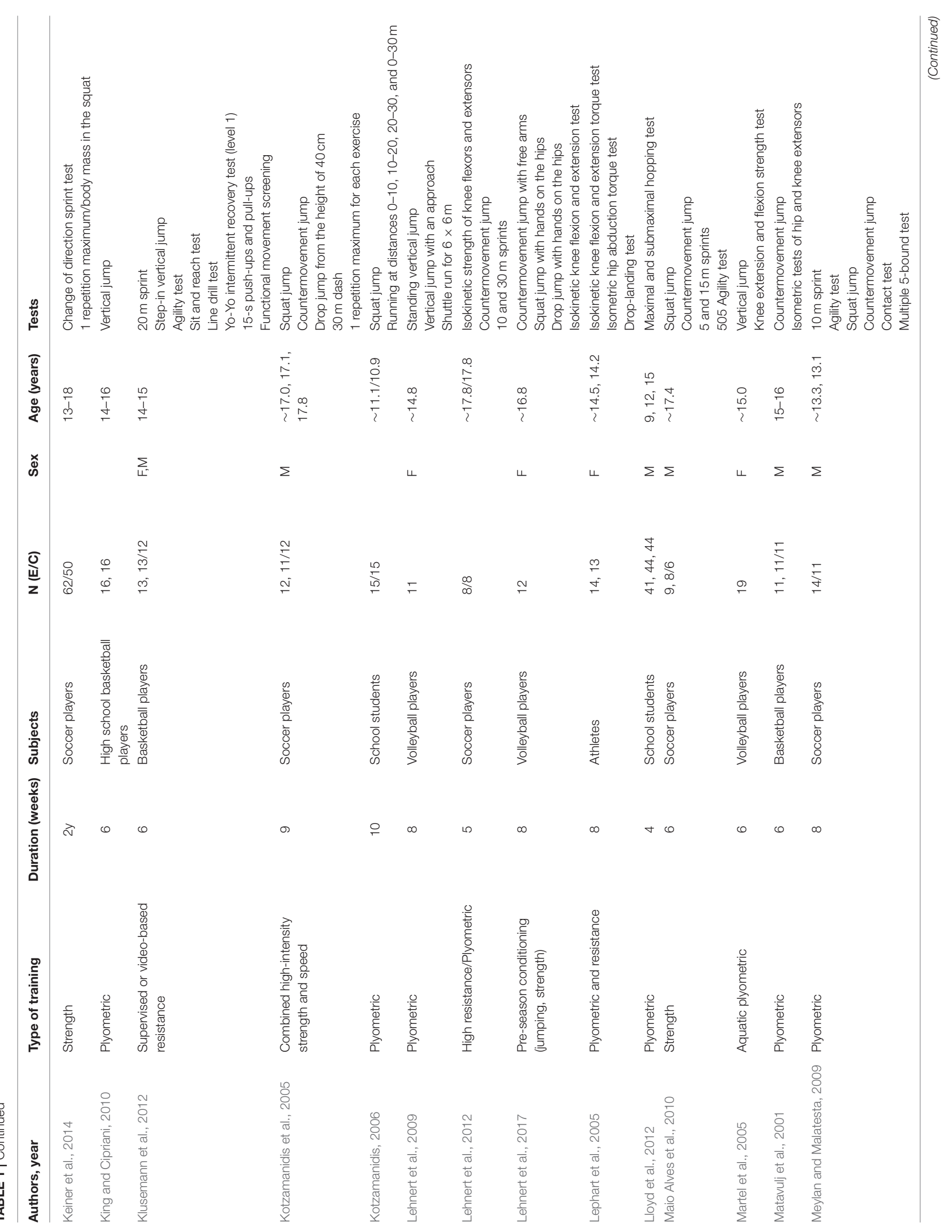




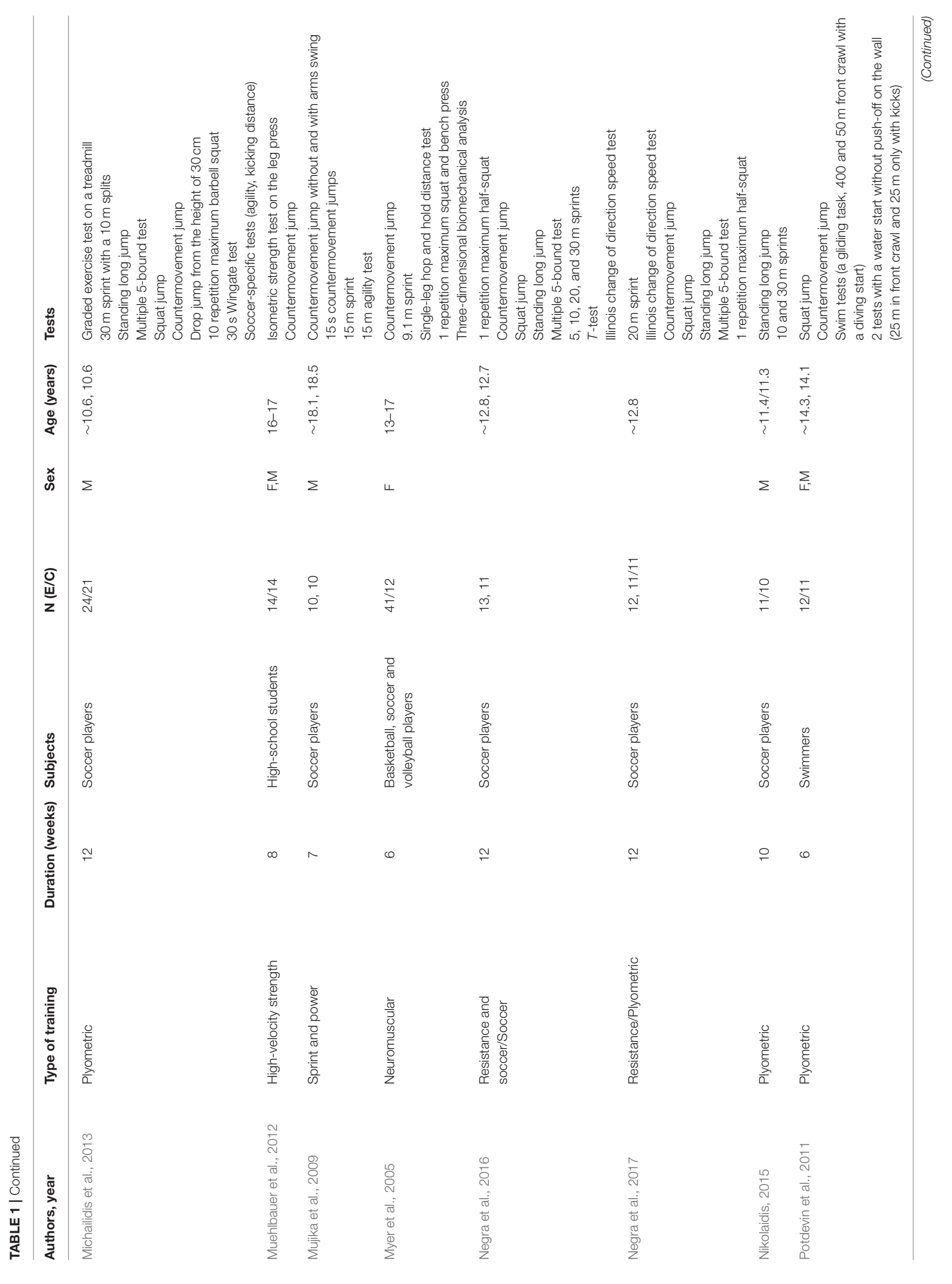


Zemková and Harar

Sport-Specific Assessment of Young Athletes

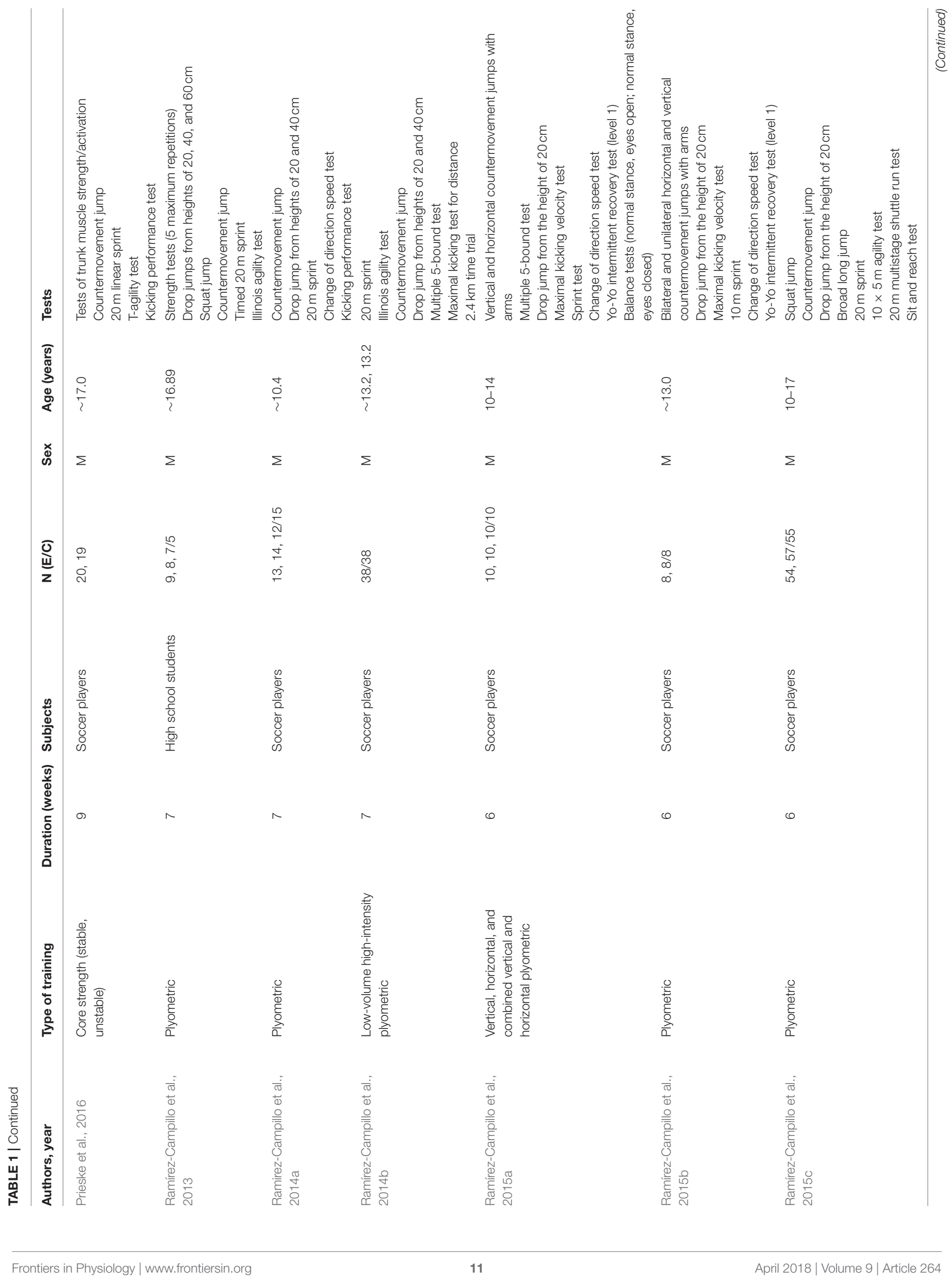




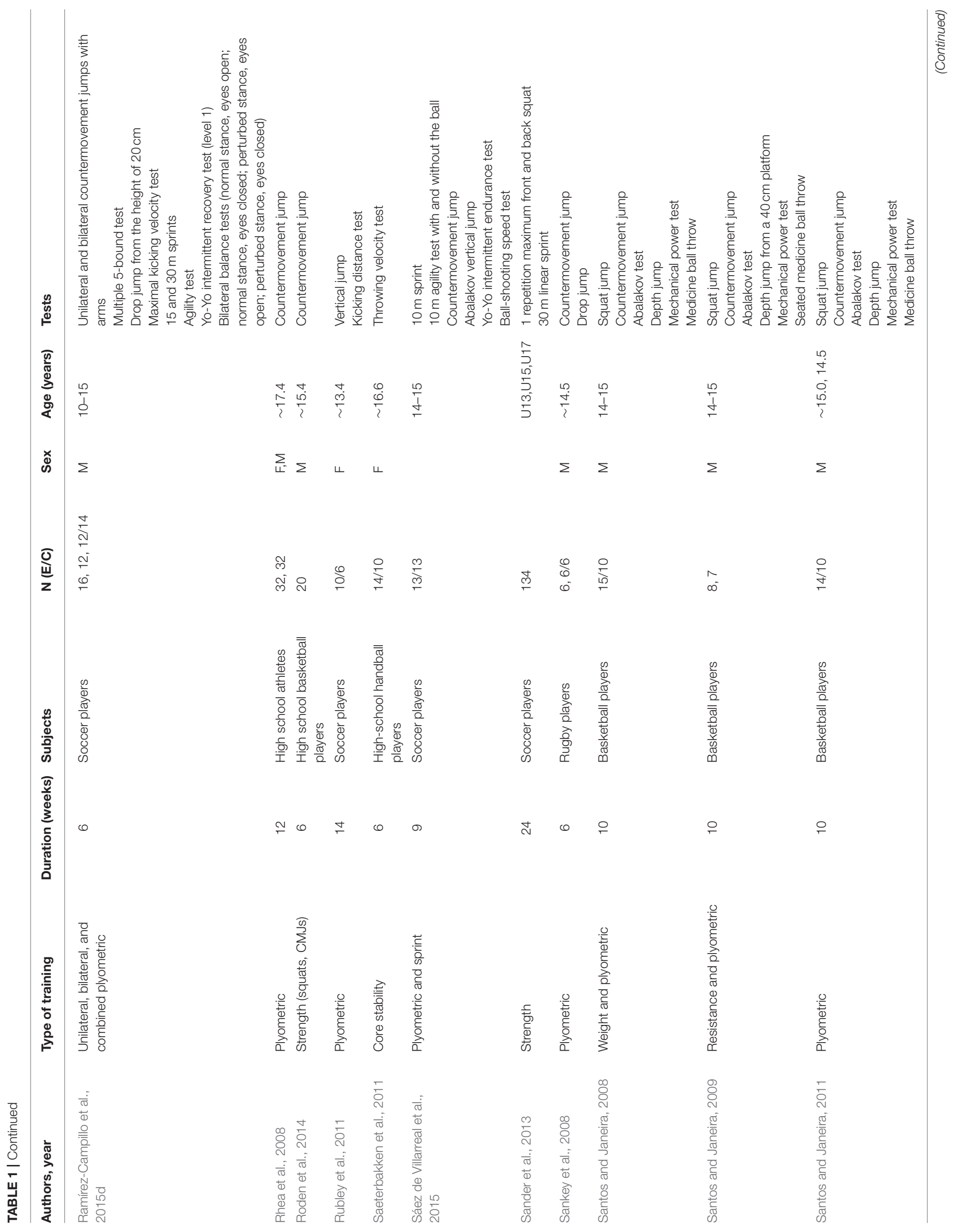




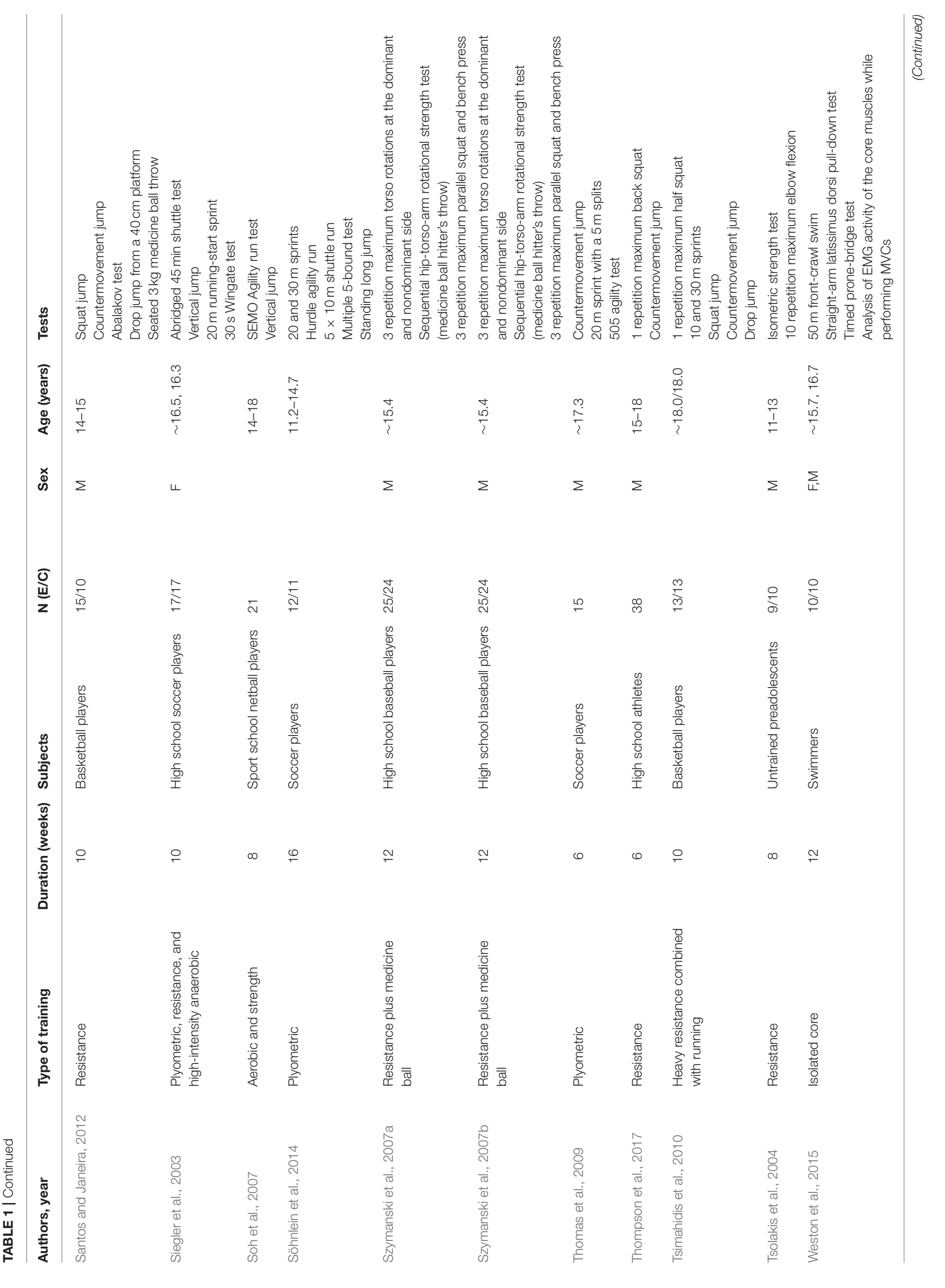


$10 \mathrm{RM}$ ) for different exercises (bench press, squat, leg press, power clean, snatch, clean \& jerk, torso rotations, etc.), isokinetic and isometric tests (back, knee extension and flexion), forcevelocity test on a cycle ergometer, $30 \mathrm{~s}$ Wingate test, standing long and vertical jumps (e.g., squat jump, countermovement jump, Abalakov test, drop jump, multiple 5 bounds test, repeated rebound jumps, triple hop test, maximal and submaximal hopping), standing and seated medicine ball throw, $15 \mathrm{~s}$ push-up or pull-up, agility tests (e.g., 505 Agility test, T-agility test, Illinois agility test, hurdle agility run, shuttle run for various distances, i.e., $6 \times 6 \mathrm{~m}, 4 \times 9 \mathrm{~m}, 4 \times 15 \mathrm{~m}, 10 \times 5 \mathrm{~m})$ and/or change of direction speed tests, sprints at different distances $(5,10,15,20$, 30 , and $40 \mathrm{~m}$ ), balance tests (e.g., bilateral stance with eyes open and eyes closed, perturbed stance with eyes open and eyes closed, Standing stork balance test, Y-balance test, Star excursion balance test, etc.), endurance tests (e.g., Yo-Yo intermittent endurance test, Yo-Yo intermittent recovery test, $20 \mathrm{~m}$ multistage shuttle run test, multistage running test on a treadmill), and flexibility tests (e.g., stand and reach, sit and reach, $\mathrm{V}$ sit and reach).

However, only few sport-specific tests were used for this purpose. These include throwing a handball ball, 10 or $15 \mathrm{~m}$ agility test with the ball, service velocity and accuracy tests in tennis, single-court and 2-court suicide runs in tennis, kicking velocity test in soccer, crossing efficiency and shooting efficiency tests in soccer, swim tests (a gliding task, 400 - and $50 \mathrm{~m}$ front crawl with a diving start), tests with a water start without pushoff on the wall ( $25 \mathrm{~m}$ in front crawl and $25 \mathrm{~m}$ only with kicks), swimming block start performance test, and so forth.

These findings indicate that moving from traditional field tests to more sophisticated testing methods evaluating athletic performance under sport-specific conditions would be a key step forward. So far, physical fitness of children and adolescents has been assessed using simple equipments (no PC-based), although various portable computerized diagnostic devices are available on the market. Therefore current test batteries should be updated. These novel batteries should be able to objectively assess athletic abilities and skills by means of novel technologies and computational techniques using for data analysis over a long-term period. This should be supported by web-based access to standard and sport-specific test protocols, management of data obtained, and their reporting. This would be the first fundamental step in proposing objective measurement tools that use technological advances in the physical fitness testing of young athletes.

\section{Long-Term Sport Diagnostic Model}

The first long-term athlete development (LTAD) model was proposed in Canada in 1998 by Dr. Istvan Balyi and was grounded around three phases: Training to Train, Training to Compete, and Training to Win. Over time, this model was evolved into seven phases: (1) Active Start, (2) FUNdamentals, (3) Learn to Train, (4) Train to Train, (5) Train to Compete, (6) Train to Win, and (7) Active for Life (Balyi et al., 2013).

Recently, Granacher et al. (2016) presented a conceptual model for the implementation of resistance training programs during the stages of long-term athlete development to enhance muscular fitness and athletic performance. According to the 
authors, long-term development of muscular fitness (strength, power, and endurance) consists of these stages: "early childhood (female: 6-8 years, male: 6-9 years) including coordination training, agility training, balance training, muscular endurance training with own body mass/training tools (e.g., medicine ball) with a focus on exercise technique; late childhood (female: 9-11 years, male: 10-13 years) including balance training, plyometric training as part of deliberate play (e.g., rope skipping) with a focus on correct jumping and landing mechanics, core strength training, muscular endurance training with own body mass/training tools (e.g., medicine ball), free weight training with a focus on exercise technique; adolescents (female: 12-18 years, male: $14-18$ years) including balance training, plyometric training (depth jumps from low drop heights), core strength training, free weight training at light to moderate loads, heavy resistance strength training (hypertrophy), eccentric resistance training, sport-specific resistance training; and adulthood (female: $>18$ years, male: $>18$ years) including balance training, plyometric training (depth jumps from moderate drop heights), core strength training, free weight training at moderate to high loads, heavy resistance strength training (neuromuscular activation + hypertrophy), sport-specific resistance training."

Taking this information into account, our previously proposed Long-Term Sport Diagnostic Model (Zemková, 2015) was modified. Age-related stages within this model are as follows: Stage 1 (6-9 years), Stage 2 ( $10-14$ years), Stage 3 ( $15-18$ years), Stage 4 (19-24 years), Stage 5 (25-44 years), Stage 6 (45-64 years), and Stage 7 (65+ years).

Targeting the young population, we have originally developed tests specifically tailored for them. So far, reliable and sensitive parameters were identified that are directly linked to the physical fitness of particular age categories and allow capture of the complexity of the performance by combining multiple parameters. Their combination showed superior results for the accurate assessment of different abilities when compared to current standard field tests. Experience showed that young people participate more intensively and also reach higher exercise goals than with conventional methods when computerized diagnostic and training systems are used. For instance, the task-oriented balance tests based on visual feedback control of body position or the agility test performed under simulated competitive conditions seem to be more suitable for children and adolescents than traditional field tests. Both of them are similar to computerized games which may enhance the attention and motivation of children to exercise. We believe that this approach may also be applied for testing of young athletes under sport-specific conditions.

Besides basic tests of reaction, agility and speed, core and postural stability, muscle strength and power, the Spinal Mouse ${ }^{\circledR}$ device was also used to assess the spinal curvature and pelvic tilt. We have tested 118 children and adolescents for sit-and-reach, passive and active straight leg raise (Muyor et al., 2014). The findings identified that the sit-and-reach test is an appropriate and valid test for the evaluation of the pelvic tilt and lumbar flexion, but not as a measure of hamstring flexibility in school age children. The active straight leg raise test may be an appropriate and easy test for the assessment of their hamstring flexibility.
It may be recommended also for young athletes as most of the authors used flexibility tests in their studies evaluating the efficiency of neuromuscular training.

The focus in the present study was given to testing of neuromuscular functions in children and adolescents (Figure 1). Proposed tests can be adjusted according to requirements of particular sports and serve as a basis for Sport-Specific Model of Athlete's Performance Testing. The motive for research in this field was our experience with several years of systematic testing of athletes, for instance, those of the National Karate Team (aged from 9 to 27 years). The most used tests were as follows: reaction test (e.g., responses to stimuli of red and blue during the strike of gyaku-cuki), hand and foot tapping, kicking velocity test, agility test, 10 and $60 \mathrm{~s}$ jump tests, $10 \mathrm{~s}$ exercise bouts at different revolution rates on the isokinetic cycle ergometer, a $30 \mathrm{~s}$ load on the isokinetic cycle ergometer or on a treadmill in the form of tethered running, and spiroergometry (Zemková and Dzurenková, 2004). Though these tests were found to be suitable for assessment of performance in karate competitors, prescribed testing protocols used in laboratories only partially fullfil the requirements for testing under sportspecific conditions. Obtaining relevant data on changes in sportspecific athlete performance during the long-term period would provide more useful information for the designing of effective training programs.

\section{Sport-Specific Assessment of Muscle Strength and Power in Young Athletes}

The ability to produce power during running, hopping and jumping improves as children grow older. The age-related increase in power production can mainly be ascribed to the increase in muscle size (Kanehisa et al., 1994; Neu et al., 2002). However, Davies and Young (1984) and Ferretti et al. (1994) showed that differences in muscle mass cannot fully explain differences in peak power between pre-adolescent children and adults. According to Ferretti et al. (1994) age-related differences in neural drive could play a role. However, Lambertz et al. (2003) found that the stiffness of the musculotendinous unit increases throughout childhood. This suggests that stiffness of lower limbs may contribute to developmental changes in jump performance (Wang et al., 2004). These findings were extended by Korff et al. (2009) who reported a significant correlation between peak power during the countermovement (CM) jump and lower limb stiffness in adolescents but not in pre-adolescents. When normalized to body mass, the relationship between peak power and stiffness of lower limbs differed similarly between these groups. These findings indicate that leg stiffness may contribute to greater power production during jumps in adolescents. On the other hand, the ability to produce power during vertical jumps in pre-adolescents is not related to the leg stiffness. This weak relationship may be explained by a greater compliance of passive elastic structures in preadolescents (Asai and Aoki, 1996; Lambertz et al., 2003). Alternatively, a lesser ability to actively stiffen their joints by antagonistic co-activation (Hortobagyi and DeVita, 2000) may result in lower ability of intersegmental control (Jensen et al., 1994). Taking into account that active (Arampatzis 
et al., 2001) as well as passive (Bobbert, 2001) stiffness components influence jump performance, pre-adolescents have a lesser ability to actively stiffen their joints to produce power (Korff et al., 2009). This may be strengthened by the greater compliance of their passive elastic structures (Lambertz et al., 2003). They can benefit from elastic energy storage in the musculotendinous system during CM jumps (Korff et al., 2009).

Therefore, the estimation of the ability to utilize elastic energy across maturational stages could provide useful information on the long-term development of jump performance and reveal potential for its trainability. From the exercise physiology it is known that activation of the stretch-shortening cycle during $\mathrm{CM}$ exercise contributes to greater power than the one performed without a prior eccentric contraction (Bosco et al., 1982). Thus, the greater jump height difference between the countermovement and the squat jump indicates an enhanced ability to utilize the elastic energy. Similar parameter can be obtained during resistance exercises performed with and without CM. Using an additional load during jumps or squats enables

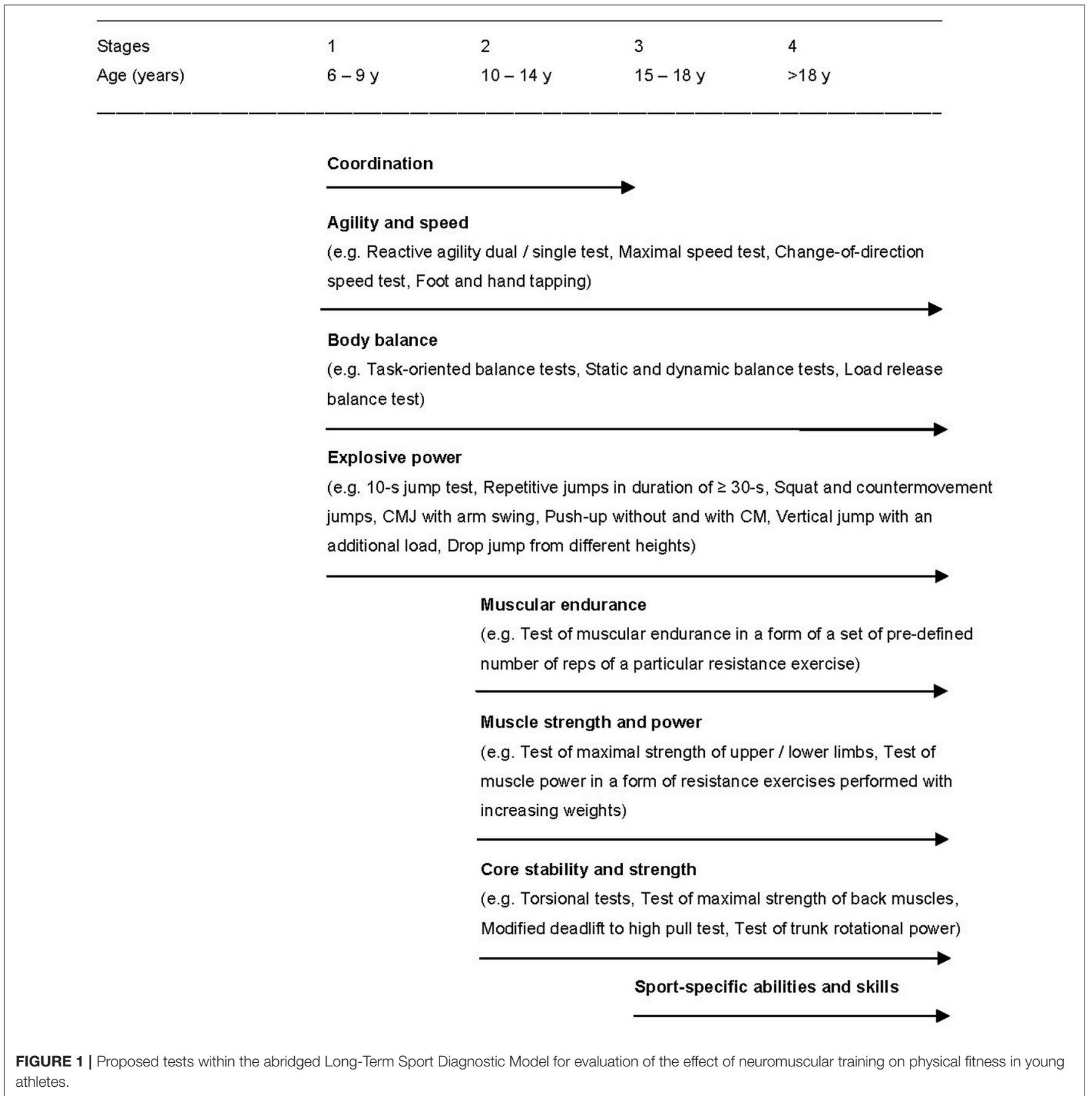


better differentiation of power performance in highly skilled athletes.

However, such an enhancement of power due to CM may differ between jumps and squats, depending on demands on the utilization of elastic energy during athlete performance (Zemková et al., 2017c). While this potentiating effect is greater during jumps than squats in high jumpers and volleyball players, opposite is true for rock \& roll competitors in acrobatics and dancing. More specifically, the values are significantly higher during squats than jumps in acrobatic rock \& roll competitors, whereas there are no differences in those who dance. On the other hand, the values are significantly higher during jumps than squats in indoor volleyball players, whereas there are no differences in those performing on the sand. Differences in CM potentiation of power in the concentric phase of jumps may also be observed in volleyball players playing different positions (spikers, blockers and setters). However, this enhancement of power during jumps and squats does not differ significantly either in hockey players or in karate competitors. These differences between groups of athletes may be ascribed to specific adaptations to exercise modes used during plyometric and resistance training.

There is a number of variations of plyometric training, including repetitive jumps on and off a box and jumping while wearing weight belts (Bobbert et al., 1996). To determine the height at which the highest power is achieved, one has to perform drop jumps, in random order, from different heights. Then, the relationship between jump height and/or power output and drop height can be described. Alternatively, the optimal drop jump height for plyometric training can be estimated.

During drop jumps, the reactive strength index (RSI), which represents a ratio of jump height and ground contact time (McClymont, 2003), is usually calculated. However, this parameter can also be calculated from repetitive jumps. There is a moderate correlation between RSI calculated from drop jump and repetitive jumps $(r=0.67)$. This method of calculating RSI from repetitive jumps may be used for athletes performing rebound jumps (e.g., aerobic \& rock and roll dancers) because it is closer to their specific demands than drop jump.

For instance, appropriate selected tests can reveal the different characteristics of jumping between male and female rock \& roll dancers. Boys' jump height is significantly higher when jumps are performed with bent knees than with straight legs. However, jump height does not differ significantly between these test conditions in girls. They achieve significantly higher power in the concentric phase of take off than boys. These differences may be attributed to similar muscle work during jumps in the test and rock \& roll performance. While girls perform bounces mainly with legs straight, boys used to jump with knees bent.

Training can lead to specific changes in power production during repetitive hopping in dancers with different forms of muscle activity during rhythmic movements. Rock \& roll dancers produce significantly higher power in the concentric phase of take-off than aerobic dancers and synchronized swimmers, concomitant with a significantly lower ground contact time. For them, the beneficial effects of an increased recoil speed from stiffer muscle-tendon units might outweigh the increased energy cost at higher jumps and contribute to lower fatigue index during such an exercise.

The fatigue index represents a decline of power during repeated vertical jumps, usually in a duration of 30,60 , or $90 \mathrm{~s}$, depending on sport specialization. Assessment of muscular endurance is of special interest in sports like aerobic gymnastics or rock \& roll, where explosive strength should be maintained for the prescribed period of the performance.

In other sports, shorter $10 \mathrm{~s}$ test of maximal jumps can be used to assess the explosive power of lower limbs. It can also be utilized for indirect estimation of muscle fiber distribution in lower limbs because there is a high correlation between the percentage of fast twitch muscle fibers in the vastus lateralis and power produced during $15 \mathrm{~s}$ jump test $(r=0.86)$ (Bosco et al., 1983). Such an information can be useful for talent identification.

As can be seen from this analysis, various approaches have been used to assess jump performance, however little is known about their advantages and limitations, particularly when testing children. Their great variability in jumping, a lack of familiarization with proper technique of the jump, or their potential learning effects in a short period of time might influence jump performance and consequently its changes across maturational stages. Therefore, there is a need to design a monitoring tool that would reveal various aspects of jump performance in the particular age, provide reliable data and be sensitive to developmental changes specifically in girls and boys.

Besides plyometric training, most of the authors in the studies analyzed used resistance exercises for the improvement of neuromuscular performance in young athletes. Estimating maximal power using the maximal effort single repetitions with increasing weights is considered as a more suitable alternative for the assessment of strength capabilities in adolescents than traditional 1 RM approach. Subjects usually perform the exercise with stepwise increasing weights up to maximal power. However, one has to be aware that maximal values of peak power and mean power in the acceleration phase of resistance exercises are achieved at lower weights than maximal values of mean power produced over the whole concentric phase, for instance at $\sim 50$ and $60 \% 1 \mathrm{RM}$ respectively during bench presses and at $\sim 70$ and 80\% 1 RM respectively during squats (Zemková et al., 2014).

Currently, instability resistance exercises are often a part of athletic and health-oriented strength training programs (Zemková, 2016c). Therefore, their role in sport-specific performance and general physical fitness is a matter of interest among conditioning specialists and researchers. We have found that measurement of peak and mean power during chest presses on a Swiss ball provides reliable data comparable to those obtained during bench presses under all conditions tested (Zemková et al., 2015a) and may represent an appropriate method for evaluation of the effects of instability resistance training. However, peak values of power measured during chest presses on an unstable surface with weights $\geq 80 \% 1 \mathrm{RM}$ should be interpreted with caution.

Besides chest presses and squats, muscle power can be evaluated via many other resistance exercises with free weights or using weight stack machines (e.g., leg press). Some examples are knee extensions and knee flexions. Mean power measured 
during these exercises is a reliable and also a sensitive parameter discriminating groups with different levels of physical activity (Zemková et al., 2015b). It can also be used for assessing the differences between the injured and non-injured leg. In addition, muscular endurance of knee extensors and knee flexors can be evaluated using the fatigue index calculated from a set of repetitions (i.e., 15). Such an assessment of muscle power during resistance exercises should be implemented in the functional diagnostics of young athletes and so complement existing testing methods.

\section{Sport-Specific Assessment of Core Stability and Strength in Young Athletes}

The importance of the function of the core for body stabilization and force generation in many sports is being recognized. The "core" is described as a box with the abdominals in the front, paraspinals and gluteals in the back, the diaphragm as the roof, and the pelvic floor and hip girdle musculature as the bottom (Richardson et al., 1999). Core strength involves the strength of trunk muscles, whereas core stability reflects the control of trunk position and its motion over the pelvis and leg in order to allow force production to the terminal segment in integrated kinetic chain exercises (Kibler et al., 2006).

Measurement of core stability involves the incorporation of variables of balance and coordination. The majority of core stability tests require the individual to keep a neutral spine in a quadrupedal or supine position (Liemohn et al., 2005; Faries and Greenwood, 2007; Gamble, 2007) that involves activation of local core muscles, such as the transversus abdominus and multifidus. Other tests assess the static muscular endurance of global core muscles, for example external obliques, quadratus lumborum and erector spinae (McGill, 2002; McGill et al., 2003; Faries and Greenwood, 2007). The most used are the BieringSørensen test of lumbar extension (Biering-Sørensen, 1984) and the flexor and side bridge endurance tests (McGill, 2001) which are exclusively performed isometrically, usually to task failure.

Another example are instrumented torsional tests, which can be performed under stable or unstable conditions. The task of the subject is to take a correct push-up position with hands on the dynamometric platform while legs are supported on the bench or physioball. Another alternative is that the subject gets into the back bridge position with legs on the dynamometric platform and back supported on the bench or physioball. These tests can also be performed in more difficult conditions with either one hand or one leg placed on the dynamometric platform. During these tests, basic stabilographic parameters are registered using the posturography system based on the dynamometric platform.

Field testing of core strength involves the amount of weight lifted, the number of repetitions performed, and the time of maintenance of neutral stable position (Faries and Greenwood, 2007). In the laboratory, isometric and isokinetic dynamometers are frequently used. In the sporting field, the back dynamometer or a potrable version of the computer-based device allowing the measurement of maximal voluntary isometric strength of predominantly back muscles can be used.

Given that muscle power is a better indicator of athletic performance, the test that measures this parameter during trunk movement may be more specific. The exercise in a form of deadlift to high pull may best mimic the demands imposed by sports comprising of lifting tasks. Muscle power measured during this exercise with free weights and on the Smith machine is a reliable and sensitive parameter able to distinguish the lifting performance in healthy young individuals (Zemková et al., 2016a).

Implements, such as the medicine ball and cable pulleys that allow motion in all three planes, can also be very useful in testing of strength and power performance. Variables of both medicine ball throws and the chop and lift have shown high reliability (Kohmura et al., 2008; Palmer and Uhl, 2011; RivillaGarcia et al., 2011; Lehman et al., 2013). Similarly, Andre et al. (2012) reported that a pulley trainer system and an external dynamometer represent a reliable tool for assessing the power during trunk rotations in a sitting position. Such a test may be appropriate for canoeing or kayaking, however for other sports, such as hockey or tennis, standing trunk rotations would be a more relevant alternative. The test adapted from the standing cable wood chop exercise on a weight stack machine is a reliable to assess the maximal power and endurance of core muscles and sensitive to differences among physically active individuals (Zemková et al., 2017a).

Such a computer-based system that can be directly connected to the weights on a stack machine is applicable for testing in fitness centers. Though machines are good for training or testing of muscle strength and power, they neglect key stabilization components of the core. Using free weights is a way to "functional" training and testing because it places greater demands on stabilizing muscles and allows a full range of trunk motion. Besides this, exercises with free weights most closely replicates the upper/lower body rotation movements. A suitable alternative represents a system consisting of an inertia measurement unit in a small box inserted on the barbell placed on the shoulders that allows evaluation of trunk rotational power in either seated or standing position. In such a case, the power is greater during standing than seated rotations of the trunk (Zemková et al., 2017b).

Typically, repetitions of a particular strength exercise with increasing weights up to the $1 \mathrm{RM}$ are performed in order to obtain force-velocity or power-velocity curves. It is known that maximum force production is achieved when the movement speed is very low (Edman et al., 1976; Thorstensson et al., 1976; Binkhorst et al., 1977; Tihanyi et al., 1982; de Koning et al., 1985; De Ruiter and De Haan, 2000). As the movement speed increases, force decreases and is very low at very high speeds. Consequently, maximal values of power occurs at intermediate velocities when lifting moderate weights (i.e., 50-60\% 1 RM) during typical resistance exercises such as bench presses or squats, whereas during trunk rotations it is at $30-45 \% 1 \mathrm{RM}$. This variation in maximal power production may be ascribed to the specificity of training adaptation.

For instance, Poór (2017) found a significant increase of mean power in the acceleration phase of trunk rotations after both the preparatory and competitive periods in tennis players at almost all weights (10-26 kg and 6-26 kg, respectively). However, its values increased significantly during trunk rotations with weights 
$\geq 12 \mathrm{~kg}$ in hockey players and with weights $\geq 10 \mathrm{~kg}$ in canoeists after the preparatory period only. These findings indicate that changes in trunk rotational power reflect the specificity of the training program.

Also within and between group differences in trunk rotational power and velocity may be attributed to specificity of the training involving trunk movements of different velocities under different load conditions. In particular, mean power and velocity in the acceleration phase of trunk rotation are sensitive parameters able to identify group and individual differences in athletes of various sports, such as karate, ice-hockey, tennis, golf, ballroom dancing, rock \& roll dancing, judo, wrestling, canoeing, rowing, weightlifting, and bodybuilding. This parameter is also specific to asymmetric loading of core muscles during trunk rotations and may identify the likelihood of low back pain. Mean power in the acceleration phase of trunk rotations is significantly higher in the dominant than non-dominant side in golfers $(11.9 \%)$ and tennis players (9.4\%), whereas there are no significant side to side differences in the group of physically fit subjects (6.2\%).

Taking into account the importance of core stability and strength in athlete's performance and probably also in the prediction of injuries, their assessment should be included in testing of young athletes. However, these tests involving lifting task or trunk rotations with an additional load must be performed with extreme caution. The exercises are usually performed with increasing weights up to maximal power rather than up to 1 RM. Preadolescents and adolescents should avoid using higher weights.

\section{Sport-Specific Assessment of Body Balance in Young Athletes}

Postural stability is maintained by three interrelated systems. The spinal column provides passive support, muscles give active support, and neural control centers coordinate sensory feedback from these systems. Traditionally, postural stability has been assessed under static conditions (bipedal or one-legged stance on a force plate with eyes open and eyes closed); however, these are not sensitive enough in discriminating athletes with good balance. Lower sensitivity of static posturography is a result of multiple sensory inputs involved in balance control that can compensate its small impairment. While standing on an unstable surface, this control mechanisms is taxed to a greater extent so that differences between individuals can be revealed. These conditions include a stance on a foam cushion, external perturbations generated from a platform either shifting in anteroposterior and medio-lateral direction or tilting toes up and down, and applying them directly to the body by pushing/pulling the trunk, shoulders or pelvis. For instance, subjects stand on a force plate connected to a computer with a special program that generates its movement in the horizontal plane. The protocol includes varied determinants of platform translation, such as the direction (forward, backward, left-lateral, and right-lateral), displacement (e.g., from 1 to $14 \mathrm{~cm}$ ), and velocity (e.g., from 5 to $20 \mathrm{~cm} / \mathrm{s}$ ). Concurrently with measurement of center of pressure (CoP) movement, trunk movement representing roughly the center of mass (CoM) can also be monitored (Zemková et al., 2016b). Experience showed that dynamic posturography is a more sensitive and also more specific alternative for most of the athletes than systems which monitor the $\mathrm{CoP}$ in static conditions. Dynamic conditions can also better reveal adaptive changes in sensorimotor functions after the training (Zemková, 2010).

However, most of the dynamic posturography systems have also shortcomings. For instance, some of the platforms are insufficient to destabilize the highly skilled athletes beyond their stability limit. Others produce only unidirectional motions in the antero-posterior plane. In the case of tilting platforms, high learning effect can be observed because the subjects can predict the upcoming perturbations relatively successfully.

Another alternative is to use instrumented tests consisting of trunk repositioning and load release tasks (Reeves et al., 2007; Silfies et al., 2007). The trunk repositioning task requires the subject to passively or actively return to a neutral spine position after a predefined displacement. The load release task requires the subject to perform an isometric contraction of trunk muscles at a predefined intensity against an external load, which is thereafter released, and the trunk displacement is evaluated. Such parameters of the load release balance test measured during standing on a foam surface are able to differentiate between sedentary and physically active adults as early as from 19 years of age (Zemková et al., 2016c).

However, in many sports athletes are forced to keep balance on an unstable surface while performing tasks of various kinds simultaneously. Being able to not only stabilize and maintain balance but also to precisely and efficiently regulate positioning of the CoM may be considered as the essence of functional balance. To assess this ability, task-oriented balance tests, such as a visually-guided CoM target-matching task or a visually-guided CoM tracking task, seem to be promising. While in the first case subjects have to hit the target randomly appearing in one of the corners of the screen by horizontal shifting of CoM in an appropriate direction; in the second they have to trace, by shifting CoM, a curve flowing either in a horizontal or vertical direction. In comparison with static balance tests, task-oriented balance tests showed comparable reliability but better potential for discriminating between groups with different levels of balance capabilities. It can also more sensitively reveal the acute and longterm effect of various sensorimotor exercises on neuromuscular performance (Zemková, 2010).

A moderate correlation between parameters of these taskoriented balance tests $(r=0.457)$ and the common variance of $13 \%$ indicates that they assess distinct qualities. This is because voluntary feedback control of body position is performed under different conditions, i.e., the subject is focused either on the goal of the task (i.e., hitting the target) or on movement themselves (i.e., the positioning of the CoM). These test differences allow assessment of accuracy of regulation of body movement that requires less or more feedback processing. This is of special importance for children who regulate their CoM movement in a more conscious, effortful fashion (i.e., observed as a longer $\mathrm{CoP}$ trajectory) with their decisions about the action being handled in a slow, attention-demanding way (i.e., shown as a slower response time). Our experience indicates that such an assessment of balance incorporating a functional task is more suitable alternative for children and adolescents than static conditions. 
The accurancy of assessment of static balance can be influenced by factors, such as motivation or attentiveness, which are difficult to control in children and adolescents. Providing immediate feedback (based on visual stimuli or statoacoustic signals) may motivate young individuals to exercise as intensively as possible while reducing the level of instructor supervision. Objective feedback also allows for adjustment of the testing protocol to specific individual needs and performance capabilities. An additional benefit is that the systems may be used as the training means. One of the alternatives are computerized balance games. These are effective in speeding the learning process by enhancing the understanding of particular tasks. Indeed, Štefániková (2013) revealed that training programs consisting of visual feedback balance exercises on either a stable or an unstable surface were more effective in improvement of balance functions than exercises on unstable surfaces without visual feedback in early school age children. This novel approach is a natural step to advancing the current state of knowledge by getting objective insight into the changes in postural control system during neuromuscular training in children and adolescents.

Utilizing techniques based on motion analysis or accelerometry recordings while evaluating head, limb and trunk movements could provide additional data and complete functional diagnostics of young athletes. The use of trunk accelerometry is a cost-effective and easily applied solution for measuring body balance and human movement. In particular, the accelerometry is a valid quantitative measure of postural sway which is strongly related to task-based measures (Whitney et al., 2011). With the advent of fast wireless technology and low-cost accelerometers, their use in field-testing of various aspects of balance is now feasible.

All these techniques can be used for assessment of postural stability in sport-specific positions or after aerobic, anaerobic and resistance exercises under laboratory and sport-specific conditions in the sporting field (Zemková, 2014). A better understanding of physiological mechanisms of post-exercise balance impairment and its readjustment to baseline (Zemková and Hamar, 2014c) may serve as a basis for the design of goal-specific balance training programs to improve athletic performance and prevent a risk of injuries.

\section{Sport-Specific Assessment of Agility and Speed in Young Athletes}

The ability to perform quick movements, stop and start rapidly while focusing on an opponent or the ball plays an essential role in athlete performance. It involves perception and decision making (cognitive processing), muscle strength and change of direction speed (motor component), in addition to footwork and movement technique (technical skills).

In comparison with traditional agility tests based on preplanned change of direction speed, novel reactive agility tests address both the cognitive (i.e., anticipation and pattern recognition) and the physical component (i.e., change of direction speed). Such testing is more sensitive in discriminating athletes of different performance levels as compared to preplanned change of direction speed tests. For instance, Sheppard et al. (2006) discovered that the reactive agility test differentiates between Australian football players of varied performance levels, whereas sprint and sprint with change of direction tests were unable to do so. Similarly, Farrow et al. (2005) found that the highly-skilled group was faster in both the planned and reactive tests than the lesser-skilled group, whereas the moderately-skilled group was faster than the lesser-skilled group in the reactive test only. Adding reactions to given stimuli into agility tests would also reflect sport-specific situations more effectively.

Both speed of decision making and change of direction speed contribute to agility performance, although to a different extent. Agility time strongly correlates with the choice reaction time, regardless of sports specialization of athletes or their previous experience with agility training. This indicates that perception and decision making are the most influential components of agility performance. There is also a significant correlation between agility time and movement time, however only when traveling a short distance. The strength of this relationship decreases with increasing traveling distances. Greater variation in the movement time than two-choice reaction time also makes potentially meaningful differences among athletes (particularly among those of combat sports and sports games) and their differential contribution to the agility performance. For instance, cognitive and motor skills are better in karate-kumite than karate-kata competitors, when only stepping reactions are required. When moving longer distances, better agility time is in players than in goalies of soccer and ball hockey. While the motor component of agility performance seems to be predominant in players in terms of faster movement execution, in goalies it is the sensory component allowing faster decision making (Zemková, 2016b).

Hence, measurements of choice reaction time and movement time or velocity, may provide useful information on these components of agility performance in athletes with different demands on their agility skills. The contribution of movement time to the agility performance may be estimated using the Agility Index (Zemková, 2016a). It is defined as a ratio of reaction time and agility time which is divided by the previously determined coefficient for each distance traveled. This index is useful for agility testing that differs in the number of stimuli and traveling distances.

As shown, agility time significantly improved after 6week training consisting of balance exercises performed simultaneously with reaction tasks (Zemková and Hamar, 2010). However, simple and two-choice reaction times did not change significantly. On the other hand, there was a significant increase in step initiation velocity. This faster execution of movement most likely contributed to the enhancement of agility performance. In fact, the reduction of agility time correlated significantly with an increase in step initiation velocity after the training $(r=0.78)$. Also of interest was the additional finding that the improvement in agility performance in older basketball players (on average 21 years) was greater than in their younger, less experienced counterparts (on average 15 years). This may be attributed to faster feedback control of movement execution, i.e., as experience level increased with practice, the agility time decreased. 
These sports (basketball, soccer, tennis, ice hockey, badminton, racquetball, squash, volleyball, baseball, softball, lacrosse, american football, wrestling, boxing, fencing) which are ranked highest for agility require changes of movement direction while responding to stimuli, such as the ball or a player. These actions in field and court sports are performed alongside the offensive player's movements, which involves some sort of competition.

In order to mimic these sport-specific demands, the agility test should be performed under simulated competitive conditions. In such a case, agility time is significantly shorter when the test is performed by two subjects simultaneously (Agility Dual) than by one subject (Agility Single) (Zemková et al., 2013). Faster agility time recorded under simulated competitive rather than non-competitive conditions (14.3\%) may be attributed to enhanced central nervous system arousal in the participants. This factor very likely contributed to a further, but not significant decrease, in agility time in the group that proceeded to the second match. Also, the learning effect may have been a factor; however this would be to a lesser extent because stimuli were randomly generated (temporally as well as spatially). The Agility Dual test should be used for testing of children and adolescents to enhance their attention and motivation. Such an exercise can also be a part of agility training in young athletes. Kováčiková (2012) found a more pronounced improvements in agility time in the Agility Dual test in the group trained under simulated competitive conditions than in the group who participated in a 8 -week training without the competitive components. It seems that agility training performed for competition is a more effective method for agility skills enhancement than the training under non-competitive conditions.

This may be beneficial for children and adolescents. It is known that agility time decreases with advancing age up to maturity (Zemková and Hamar, 2014a). Its values decrease markedly from 7 to 10 years $(27.1 \%)$ and from 10 to 14 years (26.5\%). This is followed by a slow period from 14 to 18 years (16.5\%). Participating in sport may improve their agility skills. As shown, the best agility times $(<350 \mathrm{~ms})$ are in athletes of racquet and combat sports with reactions to visual stimuli (table tennis, badminton, fencing, tae-kwon-do and karate), followed mainly by players of ball sports (ice-hockey, tennis, soccer, volleyball, basketball, and ball hockey with agility time of 350-400 ms), then competitors of combat sports with reactions to visual and tactile stimuli, such as aikido (400-450 ms), and finally judo and wrestling (450-500 ms; Zemková and Hamar, 2014b). In most of these sports, assessment of agility performance requires a specific approach. For this purpose, a number of test alternatives is available depending on the sport specific task (Zemková and Hamar, 2013). Experience showed that assessment of agility performance under sport-specific conditions represents a more appropriate method than the general version of the agility test.

If necessary, a visually-triggered step initiation test can be used to measure the time of foot off (onset of unloading) and foot flight time (from foot-off to foot-contact) of the first step. Alternatively, the speed of step initiation can be measured using the system based on precise analog velocity sensor. Maximal step velocity showed excellent reliability and also sufficient sensitivity to discriminate between individuals of different ages and levels of physical fitness.

In specific conditions, for instance in combat sports where upper and lower body extremities are utilized to punch and kick, the reaction time (onset of unloading in response to visual stimuli) and movement time (from foot-off to bag-contact) during the kick can be measured. The test is reliable and also able to distinguish between athletes of varied sports (tae-kwon-do and karate) and performance levels (kyu and dan) (Zagyi, 2010). The velocity of a punch in karate or box can be measured in a similar way.

The assessment of speed abilities can be completed by measuring the frequency of the movement of upper and lower limbs. The tapping of lower limbs can be performed in the standing or sitting position. The frequency of lower limb movements escalates with increasing age, the maximum recorded by adults, which then began to decline with increasing age ranges. Contact and flight times display a similar tendency, with the lowest values in subjects ranging from 19 to 24 years of age. Participating in sport may improve this ability. For instance, the best foot tapping frequency was recorded in boxers, followed by dancers, karate and taekwondo competitors. Its values were also significantly higher in karate competitors of more advanced (2. kyu to 2. Dan) than less skillful performance levels (7.-4. $\mathrm{kyu})$. This test can be modified by adjusting the contact mats so that specific positions in particular sports can be simulated (e.g., fighting stance in boxing, karate or tae-kwon-do) or by increasing its duration (e.g., close to duration of performance in dancing, rock \& roll or aerobics).

Additional information regarding agility and speed can be provided by using wireless timing gate systems. One has to take into account that measurement of change of direction speed may substantially differ from frequently testing straight sprinting speed by many practitioners. There is a weak relationship between change of direction speed and straight sprinting speed in highly skilled athletes. Therefore, sport-specific methods should be addressed in both the testing and training of agility skills and movement speed in young athletes.

\section{Gaps in Current Standard Testing Methods and Proposal for Future Research}

Analysis of the literature identified these gaps in current testing methods:

1) inadequacy in particular age periods (early childhood, late childhood, adolescence at pre-PHV, PHV, and post-PHV);

2) a low sensitivity to discriminate between young athletes of various ages and performance levels;

3) insufficent tailoring to athlete performance level (highly skilled athletes vs. their less proficient counterparts);

4) insufficent tailoring to individual needs (most of the studies were focused on groups of athletes rather than on individual's performance assessment);

5) a lack of specificity to the requirements of particular sports, very likely due to scarce information from experimental studies (most of the studies analyzed were related to sports games, namely soccer and basketball); 
6) a lack of specificity to reveal the effect of training, especially resistance training (while during plyometric training, a variety of jump tests was applied, in the case of resistance training, only few studies evaluated muscle power during particular resistance exercises);

7) a limited number of variables used, very likely due to diagnostic systems being used rarely, even in recent studies.

In order to partly fill in the gap in recent studies, the Sport Longlife Diagnostic Model was proposed. Its mission is to bring personalized physical fitness testing based on user-friendly computerized systems that enable full performance assessment. It develops novel testing methodologies to address and overcome the today's available field testing. It uses innovative methods to monitor and analyse the physical fitness of individuals of different ages and performance levels in a relatively short-time period. This novel approach enables testing athlete performance under sportspecific conditions. The areas of application and the number of age and sport-specific tests are constantly growing.

The model intends to innovate the assessment of physical fitness in terms of speed, safety, precision, and functionality using new generation diagnostic equipments with the goal of making testing simpler, more effective and objective. The long-term goal is to complement current diagnostic and training methods with self-monitoring devices, virtual coaching and electronic alert in order to evaluate actual athlete performance and/or health state, and the effectiveness of physical activity interventions. The self-testing and data analysis can provide a powerful alternative to current measurement tools as well as new perspectives on applications.

A database platform for the efficient management of longterm testing is being designed. It offers exercise professionals who perform athlete's assessment an integrated application for the analysis and interpretation of subject data. The entire process of the tester-subject relationship is being managed automaticallyfrom data collection, its analysis to the final report. Through this innovative approach, it feeds raw data into the database and fundamentally changes the way users can access, find, and match the results on populations tested. The database has an additional

\section{REFERENCES}

AAHPERD (1976). Youth Fitness Test Manual, Revised Edn. Washington, DC: American Alliance for Health, Physical Education, Recreation and Dance.

Alves, A. R., Marta, C. C., Neiva, H. P., Izquierdo, M., and Marques, M. C. (2016). Concurrent training in prepubescent children: the effects of 8 weeks of strength and aerobic training on explosive strength and $\mathrm{VO}_{2}$ max. J. Strength Cond. Res. 30, 2019-2032. doi: 10.1519/JSC.0000000000001294

Andre, M. J., Fry, A. C., Heyrman, M. A., Hudy, A., Holt, B., Roberts, C., et al. (2012). A reliable method for assessing rotational power. J. Strength Cond. Res. 26, 720-724. doi: 10.1519/JSC.0b013e318227664d

Andrejic, O. (2012). The effects of a plyometric and strength training program on the fitness performance in young basketball players. F.U. Phys. Ed. Sport 10, 221-229.

Annesi, J. J., Westcott, W. L., Faigenbaum, A. D., and Unruh, J. (2005). Effects of a 12-week physical activity protocol delivered by YMCA afterschool counselors (Youth Fit for Life) on fitness and self-efficacy changes potential in non-sport applications such as schools, fitness and rehabilitation centers, or medical institutions.

Diagnostic centers should serve sport professionals as well as a wide variety of people who wish to protect their health through systematic innovative assessment of their physical fitness. Integrating novel systems and methods into their daily diagnostics can enhance quality, streamline the cost of testing and bring objective data to subjects allowing repeatable evaluation before, during, and after an exercise program, treatment or rehabilitation.

The Sport Longlife Diagnostic Model would represent a significant improvement over existing field testing using computerized portable equipments and applying a set of new diagnostic tools well suited for the testing of various populations. It uses sophisticated systems and methods to detect and assess the prognosis of physical fitness, and to match the subject with objective and more effective exercise testing. It provides a valid proprietary cutting-edge functional assessment platform for athletes and physically active individuals with potential for the untrained population; people with certain diseases and those recovering from injuries. End-users can be not only sport professionals and exercise practitioners but also physical education teachers, physical therapists and physicians. In this way it can be used in gyms, fitness centers and schools, as well as in rehabilitation and medical institutions.

\section{AUTHOR CONTRIBUTIONS}

Both authors listed have made a direct and intellectual contribution to the work, and approved it for publication.

\section{ACKNOWLEDGMENTS}

This work was supported by the Slovak Research and Development Agency under the contract No. APVV-15-0704 and the Scientific Grant Agency of the Ministry of Education, Science, Research and Sport of the Slovak Republic and the Slovak Academy of Sciences (No. 1/0824/17). in 5-12 year old boys and girls. Res. Q. Exerc. Sport 76, 468-476. doi: 10.1080/02701367.2005.10599320

Arampatzis, A., Schaade, F., Walsh, M., and Bruggemann, G. P. (2001). Influence of leg stiffness and its effect on myodynamic jumping performance. $J$. Electromyogr. Kinesiol. 11, 355-364. doi: 10.1016/S1050-6411(01)00009-8

Asai, H., and Aoki, J. (1996). Force development of dynamic and static contractions in children and adults. Int. J. Sports Med. 17, 170-174. doi: 10.1055/s-2007-972827

Assunção, A. R., Bottaro, M., Cardoso, E. A., Dantas da Silva, D. P., Ferraz, M., Vieira, C. A., et al. (2017). Effects of a low-volume plyometric training in anaerobic performance of adolescent athletes. J. Sports Med. Phys. Fitness. doi: 10.23736/S0022-4707.17.07173-0. [Epub ahead of print].

Balyi, I., Way, R., and Higgs, C. (2013). Long-Term Athlete Development. Champaign, IL: Human Kinetics.

Barber-Westin, S. D., Hermeto, A. A., and Noyes, F. R. (2010). A six-week neuromuscular training program for competitive junior tennis players. $J$. Strength Cond. Res. 24, 2372-2382. doi: 10.1519/JSC.0b013e3181e8a47f 
Behringer, M., Neuerburg, S., Matthews, M., and Mester, J. (2013). Effects of two different resistance-training programs on mean tennis-serve velocity in adolescents. Pediatr. Exerc. Sci. 25, 370-384. doi: 10.1123/pes.25.3.370

Benson, A. C., Torode, M. E., and Fiatarone Singh, M. A. (2007). A rational and method for high-intensity progressive resistance training with children and adolescents. Contemp. Clin. Trials 28, 442-450. doi: 10.1016/j.cct.2006.11.004

Biering-Sørensen, F. (1984). Physical measurements as risk indicators for low-back trouble over a one-year period. Spine 9, 106-119. doi: 10.1097/00007632-198403000-00002

Binkhorst, R. A., Hoofd, L., and Vissers, A. C. (1977). Temperature and forcevelocity relationship of human muscles. J. Appl. Physiol. Respir. Environ. Exerc. Physiol. 42, 471-475.

Bishop, D. C., Smith, R. J., Smith, M. F., and Rigby, H. E. (2009). Effect of plyometric training on swimming block start performance in adolescents. J. Strength Cond. Res. 23, 2137-2143. doi: 10.1519/JSC.0b013e3181b866d0

Bobbert, M. F. (2001). Dependence of human squat jump performance on the series elastic compliance of the triceps surae: a simulation study. J. Exp. Biol. 204, 533-542.

Bobbert, M. F., Gerritsen, K. G., Litjens, M. C., and Van Soest, A. J. (1996). Why is countermovement jump height greater than squat jump height? Med. Sci. Sports Exerc. 28, 1402-1412. doi: 10.1097/00005768-199611000-00009

Bosco, C., Viitasalo, J. T., Komi, P. V., and Luhtanen, P. (1982). Combined effect of elastic energy and myoelectrical potentiation during stretch-shortening cycle exercise. Acta Physiol. Scand. 114, 557-565. doi: 10.1111/j.1748-1716.1982.tb07024.x

Bosco, C., Komi, P. V., Tihanyi, J., Fekete, G., and Apor, P. (1983). Mechanical power test and fiber composition of human leg extensor muscles. Eur. J. Appl. Physiol. 50, 129-136. doi: 10.1007/BF009 52545

Brown, M. E., Mayhew, J. L., and Boleach, L. W. (1986). Effect of plyometric training on vertical jump performance in high-school basketball players. J. Sports Med. Phys. Fitness 26, 1-4.

Buchheit, M., Mendez-Villanueva, A., Delhomel, G., Brughelli, M., and Ahmaidi, S. (2010a). Improving repeated sprint ability in young elite soccer players: repeated shuttle sprints vs. explosive strength training. J. Strength Cond. Res. 24, 2715-2722. doi: 10.1519/JSC.0b013e3181bf0223

Buchheit, M., Mendez-Villanueva, A., Quod, M., Quesnel, T., and Ahmaidi, S. (2010b). Improving acceleration and repeated sprint ability in well-trained adolescent handball players: speed versus sprint interval training. Int. J. Sports Physiol. Perform. 5, 152-164. doi: 10.1123/ijspp.5.2.152

CAHPER (1980). Fitness Performance II Test Manual. Ottawa, ON: Canadian Association for Health, Physical Education and Recreation.

Cavaco, B., Sousa, N., Dos Reis, V. M., Garrido, N., Saavedra, F., Mendes, R., et al. (2014). Short-term effects of complex training on agility with the ball, speed, efficiency of crossing and shooting in youth soccer players. J. Hum. Kinet. 43, 105-112. doi: 10.2478/hukin-2014-0095

Channell, B. T., and Barfield, J. P. (2008). Effect of Olympic and traditional resistance training on vertical jump improvement in high school boys. $J$. Strength Cond. Res. 22, 1522-1527. doi: 10.1519/JSC.0b013e318181a3d0

Chaouachi, A., Othman, A. B., Hammami, R., Drinkwater, E. J., and Behm, D. G. (2014). The combination of plyometric and balance training improves sprint and shuttle run performances more often than plyometric-only training with children. J. Strength Cond. Res. 28, 401-412. doi: 10.1519/JSC.0b013e3182987059

Chaouachi, M., Granacher, U., Makhlouf, I., Hammami, R., Behm, D. G., and Chaouachi, A. (2017). Within session sequence of balance and plyometric exercises does not affect training adaptations with youth soccer athletes. $J$. Sports Sci. Med. 16, 125-136.

Chelly, M. S., Fathloun, M., Cherif, N., Ben Amar, M., Tabka, Z., and Van Praagh, E. (2009). Effects of a back squat training program on leg power, jump, and sprint performances in junior soccer players. J. Strength Cond. Res. 23, 2241-2249. doi: 10.1519/JSC.0b013e3181b86c40

Chelly, M. S., Hermassi, S., Aouadi, R., and Shephard, R. J. (2014). Effects of 8 -week in-season plyometric training on upper and lower limb performance of elite adolescent handball players. J. Strength Cond. Res. 28, 1401-1410. doi: 10.1519/JSC.0000000000000279

Chelly, M. S., Hermassi, S., and Shephard, R. J. (2015). Effects of in-season short-term plyometric training program on sprint and jump performance of young male track athletes. J. Strength Cond. Res. 29, 2128-2136. doi: 10.1519/JSC.0000000000000860

Christou, M., Smilios, I., Sotiropoulos, K., Volaklis, K., Pilianidis, T., and Tokmakidis, S. P. (2006). Effects of resistance training on the physical capacities of adolescent soccer players. J. Strength Cond. Res. 20, 783-791. doi: 10.1519/R-17254.1

Council of Europe, Committee for the Development of Sport (1993). Eurofit: Handbook for the Eurofit Tests of Physical Fitness, 2nd Edn. Strasbourg: Council of Europe, Committee for the Development of Sport.

Coutts, A. J., Murphy, A. J., and Dascombe, B. J. (2004). Effect of direct supervision of a strength coach on measures of muscular strength and power in young rugby league players. J. Strength Cond. Res. 18, 316-323. doi: 10.1519/R-12972.1

da Fontoura, A. S., Schneider, P., and Meyer, F. (2004). Effect of the muscular strength detraining in prepubertal boys. Rev. Bras. Med. Esporte 10, 285-288. doi: 10.1590/S1517-86922004000400005

Davies, C. T., and Young, K. (1984). Effects of external loading on short term power output in children and young male adults. Eur. J. Appl. Physiol. Occup. Physiol. 52, 351-354. doi: 10.1007/BF01015226

de Koning, F. L., Binkhorst, R. A., Vos, J. A., and van 't Hof, M. A. (1985). The force-velocity relationship of arm flexion in untrained males and females and arm-trained athletes. Eur. J. Appl. Physiol. Occup. Physiol. 54, 89-94. doi: $10.1007 / \mathrm{BF} 00426305$

De Ruiter, C. J., and De Haan, A. (2000). Temperature effect on the force/velocity relationship of the fresh and fatigued human adductor pollicis muscle. Pflugers Arch. 440, 163-170. doi: 10.1007/s004240000284

Diallo, O., Dore, E., Duche, P., and Van Praagh, E. (2001). Effects of plyometric training followed by a reduced training programme on physical performance in prepubescent soccer players. J. Sports Med. Phys. Fitness 41, 342-348.

Drinkwater, E. J., Lawton, T. W., Lindsell, R. P., Pyne, D. B., Hunt, P. H., and McKenna, M. J. (2005). Training leading to repetition failure enhances bench press strength gains in elite junior athletes. J. Strength Cond. Res. 19, 382-388. doi: 10.1519/R-15224.1

Edman, K. A., Mulieri, L. A., and Scubon-Mulieri, B. (1976). Non-hyperbolic forcevelocity relationship in single muscle fibres. Acta Physiol. Scand. 98, 143-156. doi: 10.1111/j.1748-1716.1976.tb00234.x

Escamilla, R. F., Fleisig, G. S., Yamashiro, K., Mikla, T., Dunning, R., Paulos, L., et al. (2010). Effects of a 4-week youth baseball conditioning program on throwing velocity. J. Strength Cond. Res. 24, 3247-3254. doi: 10.1519/JSC.0b013e3181db9f59

Faigenbaum, A. D., Zaichkowsky, L. D., Westcott, W. L., Micheli, L., and Fernandez- Garcia, J. M. (1993). The effects of twice-a-week strength training program on children. Pediatr. Exerc. Sci. 5, 339-346. doi: 10.1123/pes.5.4.339

Faigenbaum, A. D., Westcott, W. L., Micheli, L. J., Outerbridge, A. R., Long, C. J., LaRosa-Loud, R., et al. (1996). The effects of strength training and detraining on children. J. Strength Cond. Res. 10, 109-114. 2.3. doi: 10.1519/1533-4287(1996)010<0109:TEOSTA >2.3.CO;2

Faigenbaum, A. D., Westcott, W. L., Loud, R. L., and Long, C. (1999). The effects of different resistance training protocols on muscular strength and endurance development in children. Pediatrics 104:e5.

Faigenbaum, A. D., Loud, R. L., O'Connell, J., Glover, S., O'Connell, J., and Westcott, W. L. (2001). Effects of different resistance training protocols on upper-body strength and endurance development in children. J. Strength Cond. Res. 15, 459-465. doi: 10.1519/00124278-200111000-00010

Faigenbaum, A. D., Milliken, L. A., Loud, R. L., Burak, B. T., Doherty, C. L., and Westcott, W. L. (2002). Comparison of 1 and 2 days per week of strength training in children. Res. Q. Exerc. Sport 73, 416-424. doi: 10.1080/02701367.2002.10609041

Faigenbaum, A. D., Milliken, L., Moulton, L., and Westcott, W. L. (2005). Early muscular fitness adaptations in children in response to two different resistance training regimens. Pediatr. Exerc. Sci. 17, 237-248. doi: 10.1123/pes. 17.3.237

Faigenbaum, A. D., and Mediate, P. (2006). Effects of medicine ball training on fitness performance of high-school physical education students. Phys. Educ. 63, 160-167.

Faigenbaum, A. D., McFarland, J. E., Keiper, F. B., Tevlin, W., Ratamess, N. A., Kang, J., et al. (2007a). Effects of a short-term plyometric and resistance training program on fitness performance in boys age 12 to 15 years. J. Sports Sci. Med. 6, 519-525. 
Faigenbaum, A., McFarland, J., Johnson, L., Kang, J., Bloom, J., Ratamess, N., et al. (2007b). Preliminary evaluation of an after-school resistance training program for improving physical fitness in middle-school-aged boys. Percept. Mot. Skills 104, 407-415. doi: 10.2466/pms.104.2.407-415

Faigenbaum, A., Farrell, A. C., Radler, T., Zbojovsky, D., Chu, D. A., Ratamess, N. A., et al. (2009). "PlyoPlay" A novel program of short bouts of moderate and high intensity exercise improves physical fitness in elementary school children. Phys. Educ. 66, 37-44.

Faigenbaum, A. D., Farrell, A. C., Fabiano, M., Radler, T. A., Naclerio, F., Ratamess, N. A., et al. (2013). Effects of detraining on fitness performance in 7-year-old children. J. Strength Cond. Res. 27, 323-230. doi: 10.1519/JSC.0b013e31827e135b

Falk, B., and Mor, G. (1996). The effects of resistance and martial arts training in 6 to 8 year old boys. Pediatr. Exerc. Sci. 8, 48-56. doi: 10.1123/pes.8.1.48

Faries, M. D., and Greenwood, M. (2007). Core training: stabilizing the confusion. Strength Cond. J. 29, 10-25. doi: 10.1519/00126548-200704000-00001

Farrow, D., Young, W., and Bruce, L. (2005). The development of a test of reactive agility for netball: a new methodology. J. Sci. Med. Sport 8, 52-60. doi: 10.1016/S1440-2440(05)80024-6

Fernandez-Fernandez, J., Ellenbecker, T., Sanz-Rivas, D., Ulbricht, A., and Ferrautia, A. (2013). Effects of a 6-week junior tennis conditioning program on service velocity. J. Sports Sci. Med. 12, 232-239.

Ferrete, C., Requena, B., Suarez-Arrones, L., and de Villarreal, E. S. (2014). Effect of strength and high-intensity training on jumping, sprinting, and intermittent endurance performance in prepubertal soccer players. J. Strength Cond. Res. 28, 413-422. doi: 10.1519/JSC.0b013e31829b2222

Ferretti, G., Narici, M. V., Binzoni, T., Gariod, L., LeBas, J. F., Reutenauer, H., et al. (1994). Determinants of peak muscle power: effects of age and physical conditioning. Eur. J. Appl. Physiol. Occup. Physiol. 68, 111-115.doi: 10.1007/BF00244022

Filipa, A., Byrnes, R., Paterno, M. V., Myer, G. D., and Hewett, T. E. (2010). Neuromuscular training improves performance on the star excursion balance test in young female athletes. J. Orthop. Sports Phys. Ther. 40, 551-558. doi: 10.2519 /jospt.2010.3325

Flanagan, S. P., Laubach, L. L., De Marco, G. M. Jr., Alvarez, C., Borchers, S., Dressman, E., et al. (2002). Effects of two different strength training modes on motor performance in children. Res. Q. Exerc. Sport 73, 340-344. doi: 10.1080/02701367.2002.10609029

Gabbett, T. J., Johns, J., and Riemann, M. (2008). Performance changes following training in junior rugby league players. J. Strength Cond. Res. 22, 910-917. doi: 10.1519/JSC.0b013e31816a5fa5

Gamble, P. (2007). An integrated approach to training core stability. Strength Cond. J. 29, 56-68. doi: 10.1519/00126548-200702000-00010

González-Badillo, J. J., Gorostiaga, E. M., Arellano, R., and Izquierdo, M. (2005). Moderate resistance training volume produces more favorable strength gains than high or low volumes during a short-term training cycle. J. Strength Cond. Res. 19, 689-697. doi: 10.1519/R-15574.1

González-Badillo, J. J., Izquierdo, M., and Gorostiaga, E. M. (2006). Moderate volume of high relative training intensity produces greater strength gains compared with low and high volumes in competitive weightlifters. J. Strength Cond. Res. 20, 73-81. doi: 10.1519/R-16284.1

Gorostiaga, E. M., Izquierdo, M., Iturralde, P., Ruesta, M., and Ibanez, J. (1999). Effects of heavy resistance training on maximal and explosive force production, endurance and serum hormones in adolescent handball players. Eur. J. Appl. Physiol. Occup. Physiol. 80, 485-493. doi: 10.1007/s004210050622

Gorostiaga, E. M., Izquierdo, M., Ruesta, M., Iribarren, J., Gonzalez-Badillo, J. J., and Ibanez, J. (2004). Strength training effects on physical performance and serum hormones in young soccer players. Eur. J. Appl. Physiol. 91, 698-707. doi: 10.1007/s00421-003-1032-y

Granacher, U., Muehlbauer, T., Doerflinger, B., Strohmeier, R., and Gollhofer, A. (2011). Promoting strength and balance in adolescents during physical education: effects of a short-term resistance training. J. Strength Cond. Res. 25, 940-949. doi: 10.1519/JSC.0b013e3181c7bble

Granacher, U., Schellbach, J., Klein, K., Prieske, O., Baeyens, J. P., and Muehlbauer, T. (2014). Effects of core strength training using stable versus unstable surfaces on physical fitness in adolescents: a randomized controlled trial. BMC Sports Sci. Med. Rehabil. 6:40. doi: 10.1186/2052-1847-6-40
Granacher, U., Prieske, O., Majewski, M., Büsch, D., and Muehlbauer, T. (2015). The role of instability with plyometric training in sub-elite adolescent soccer players. Int. J. Sports Med. 36, 386-394. doi: 10.1055/s-0034-1395519

Granacher, U., Lesinski, M., Büsch, D., Muehlbauer, T., Prieske, O., Puta, C., et al. (2016). Effects of resistance training in youth athletes on muscular fitness and athletic performance: a conceptual model for long-term athlete development. Front. Physiol. 7:164. doi: 10.3389/fphys.2016.00164

Hammami, R., Granacher, U., Makhlouf, I., Behm, D. G., and Chaouachi, A. (2016). Sequencing effects of balance and plyometric training on physical performance in youth soccer sthletes. J. Strength Cond. Res. 30, 3278-3289. doi: 10.1519/JSC.0000000000001425

Häkkinen, K., Mero, A., and Kauhanen, H. (1989). Specificity of endurance, sprint and strength training on physical performance capacity in young athletes. $J$. Sports Med. Phys. Fitness 29, 27-35.

Hortobagyi, T., and DeVita, P. (2000). Muscle pre- and coactivity during downward stepping are associated with leg stiffness in aging. J. Electromyogr. Kinesiol. 10, 117-126. doi: 10.1016/S1050-6411(99)00026-7

Jensen, J. L., Phillips, S. J., and Clark, J. E. (1994). For young jumpers, differences are in the movement's control, not its coordination. Res. Q. Exerc. Sport 65, 258-268. doi: 10.1080/02701367.1994.10607627

Kanehisa, H., Ikegawa, S., Tsunoda, N., and Fukunaga, T. (1994). Strength and cross-sectional area of knee extensor muscles in children. Eur. J. Appl. Physiol. Occup. Physiol. 68, 402-405. doi: 10.1007/BF00843736

Keiner, M., Sander, A., Wirth, K., and Schmidtbleicher, D. (2014). Long-term strength training effects on change-of-direction sprint performance. J. Strength Cond. Res. 28, 223-231. doi: 10.1519/JSC.0b013e318295644b

Kibler, W. B., Press, J., and Sciascia, A. (2006). The role of core stability in athletic function. Sports Med. 36, 189-198. doi: 10.2165/00007256-200636030-00001

King, J. A., and Cipriani, D. J. (2010). Comparing preseason frontal and sagittal plane plyometric programs on vertical jump height in high-school basketball players. J. Strength Cond. Res. 24, 2109-2114. doi: 10.1519/JSC.0b013e3181e347d1

Klusemann, M. J., Pyne, D. B., Fay, T. S., and Drinkwater, E. J. (2012). Online video-based resistance training improves the physical capacity of junior basketball athletes. J. Strength Cond. Res. 26, 2677-2684. doi: 10.1519/JSC.0b013e318241b021

Kohmura, Y., Aoki, K., Yoshigi, H., Sakuraba, K., and Yanagiya, T. (2008). Development of a baseball-specific battery of tests and a testing protocol for college baseball players. J. Strength Cond. Res. 22, 1051-1058. doi: 10.1519/JSC.0b013e31816eb4ef

Korff, T., Horne, S. L., Cullen, S. J., and Blazevich, A. J. (2009). Development of lower limb stiffness and its contribution to maximum vertical jumping power during adolescence. J. Exp. Biol. 212, 3737-3742. doi: 10.1242/jeb.033191

Kotzamanidis, C., Chatzopoulos, D., Michailidis, C., Papaiakovou, G., and Patikas, D. (2005). The effect of a combined high-intensity strength and speed training program on the running and jumping ability of soccer players. J. Strength Cond. Res. 19, 369-375. doi: 10.1519/R-14944.1

Kotzamanidis, C. (2006). Effect of plyometric training on running performance and vertical jumping in prepubertal boys. J. Strength Cond. Res. 20, 441-445. doi: 10.1519/R-16194.1

Kováčiková, Z. (2012). Zmeny Reakčno-Rýchlostných Schopností po Rôznych Formách Agility Tréningu [Changes in Reaction-Speed Abilities After Various Forms of Agility Training]. Ph.D. thesis, Comenius University in Bratislava, Faculty of Physical Education and Sport, Bratislava.

Lambertz, D., Mora, I., Grosset, J. F., and Perot, C. (2003). Evaluation of musculotendinous stiffness in prepubertal children and adults, taking into account muscle activity. J. Appl. Physiol. 95, 64-72. doi: 10.1152/japplphysiol.00885.2002

Lehman, G., Drinkwater, E. J., and Behm, D. G. (2013). Correlation of throwing velocity to the results of lower-body field tests in male college baseball players. J. Strength Cond. Res. 27, 902-908. doi: 10.1519/JSC.0b013e3182606c79

Lehnert, M., Lamrová, I., and Elfmark, M. (2009). Changes in speed and strength in female volleyball players during and after a plyometric training program. Acta Univ. Palacki. Olomuc. Gymn. 39, 59-66. doi: 10.1016/j.jsams.2012.02.004

Lehnert, M., Psotta, R., and Botek, Z. (2012). The effects of high-resistance and plyometric training on adolescent soccer players: a comparative study. Gazz. Med. Ital. Arch. Sci. Med. 171, 567-576. 
Lehnert, M., Sigmund, M., Vareková, R., Hroch, M., Xaverová, Z., and Háp, P. (2017). Training-induced changes in physical performance can be achieved without body mass reduction after eight week of strength and injury prevention oriented programme in volleyball female players. Biol. Sport 34, 205-213. doi: 10.5114/biolsport.2017.65995

Lephart, S. M., Abt, J. P., Ferris, C. M., Sell, T. C., Nagai, T., Myers, J. B., et al. (2005). Neuromuscular and biomechanical characteristic changes in high school athletes: a plyometric versus basic resistance program. Br. J. Sports Med. 39, 932-938. doi: 10.1136/bjsm.2005.019083

Liemohn, W. P., Baumgartner, T. A., and Gagnon, L. H. (2005). Measuring core stability. J. Strength Cond. Res. 19, 583-586. doi: 10.1519/15334287(2005)19[583:MCS]2.0.CO;2

Lloyd, R. S., Oliver, J. L., Hughes, M. G., and Williams, C. A. (2012). The effects of 4-weeks of plyometric training on reactive strength index and leg stiffness in male youths. J. Strength Cond. Res. 26, 2812-2819. doi: 10.1519/JSC.0b013e318242d2ec

Maio Alves, J. M., Rebelo, A. N., Abrantes, C., and Sampaio, J. (2010). Shortterm effects of complex and contrast training in soccer players' vertical jump, sprint, and agility abilities. J. Strength Cond. Res. 24, 936-941. doi: 10.1519/JSC.0b013e3181c7c5fd

Martel, G. F., Harmer, M. L., Logan, J. M., and Parker, C. B. (2005). Aquatic plyometric training increases vertical jump in female volleyball players. Med. Sci. Sports Exerc. 37, 1814-1819. doi: 10.1249/01.mss.0000184289.87574.60

Matavulj, D., Kukolj, M., Ugarkovic, D., Tihanyi, J., and Jaric, S. (2001). Effects of plyometric training on jumping performance in junior basketball players. J. Sports Med. Phys. Fitness 41, 159-164.

McClymont, D. (2003). "Use of the reactive strength index (RSI) as an indicator of plyometric training conditions," in 5th World Conference on Science and Football, eds T. Reilly, J. Cabri, D. Araujo, (Lisbon), 408-416.

McGill, S. M. (2001). Low back stability: from formal description to issues for performance and rehabilitation. Exerc. Sport Sci. Rev. 29, 26-31. doi: 10.1097/00003677-200101000-00006

McGill, S. M. (2002). Low Back Disorders: Evidence-Based Prevention and Rehabilitation. Champaign, IL: Human Kinetics.

McGill, S., Grenier, S., Bluhm, M., Preuss, R., Brown, S. H., and Russell, C. (2003). Previous history of LBP with work loss is related to lingering deficits in biomechanical, physiological, personal, psychosocial and motor control characteristics. Ergonomics 46, 731-746. doi: 10.1080/0014013031000090134

Meylan, C., and Malatesta, D. (2009). Effects of in-season plyometric training within soccer practice on explosive actions of young players. J. Strength Cond. Res. 23, 2605-2613. doi: 10.1519/JSC.0b013e3181b1f330

Michailidis, Y., Fatouros, I. G., Primpa, E., Michailidis, C., Avloniti, A., Chatzinikolaou, A., et al. (2013). Plyometrics' trainability in pre-adolescent soccer athletes. J. Strength Cond. Res. 27, 38-49. doi: 10.1519/JSC.0b013e3182541ec6

Muehlbauer, T., Gollhofer, A., and Granacher, U. (2012). Sex-related effects in strength training during adolescence: a pilot study. Percept. Mot. Skills 115, 953-968. doi: 10.2466/06.10.30.PMS.115.6.953-968

Mujika, I., Santisteban, J., and Castagna, C. (2009). In-season effect of short-term sprint and power training programs on elite junior soccer players. J. Strength Cond. Res. 23, 2581-2587. doi: 10.1519/JSC.0b013e3181bclaac

Muyor, J. M., Zemková, E., Štefániková, G., and Kotyra, M. (2014). Concurrent validity of clinical tests for measuring hamstring flexibility in school age children. Int. J. Sports Med. 35, 664-669. doi: 10.1055/s-0033-1353217

Myer, G. D., Ford, K. R., Palumbo, J. P., and Hewett, T. E. (2005). Neuromuscular training improves performance and lower-extremity biomechanics in female athletes. J. Strength Cond. Res. 19, 51-60. doi: 10.1519/13643.1

Negra, Y., Chaabene, H., Hammami, M., Hachana, Y., and Granacher, U. (2016). Effects of high-velocity resistance training on athletic performance in prepuberal male soccer athletes. J. Strength Cond. Res. 30, 3290-3297. doi: $10.1519 /$ JSC. 0000000000001433

Negra, Y., Chaabene, H., Stöggl, T., Hammami, M., Chelly, M. S., and Hachana, Y. (2017). Effectiveness and time-course adaptation of resistance training vs. plyometric training in prepubertal soccer players. J. Sport Health Sci. doi: 10.1016/j.jshs.2016.07.008. [Epub ahead of print].

Neu, C. M., Rauch, F., Rittweger, J., Manz, F., and Schoenau, E. (2002). Influence of puberty on muscle development at the forearm. Am. J. Physiol. Endocrinol. Metab. 283, E103-E107. doi: 10.1152/ajpendo.00445.2001
Nikolaidis, P. T. (2015). Effect of plyometric training on athletic performance in preadolescent soccer players. J. Hum. Sport Exerc. 10, 15-23. doi: 10.14198/jhse.2015.101.02

Palmer, T. G., and Uhl, T. L. (2011). Interday reliability of peak muscular power outputs on an isotonic dynamometer and assessment of active trunk control using the Chop and Lift tests. J. Athl. Train. 46, 150-159. doi: $10.4085 / 1062-6050-46.2 .150$

Plowman, S. A., Sterling, C. L., Corbin, C. B., Meredith, M. D., Welk, G. J., and Morrow, J. R. (2006). The History of FITNESSGRAM ${ }^{\circledR}$. J. Phys. Act. Health 3 , S5-S20. doi: 10.1123/jpah.3.s2.s5

Poór, O. (2017). Zmeny Svalového Výkonu pri Rotačnom Pohybe Trupu v Prípravnom a Sútažnom Obdobi Športovcov Rôznych Špecializácii [Changes in Muscle Power During Trunk Rotational Movement in the Preparatory and Competitive Period in Athletes of Various Specializations]. Undefended dissertation thesis.

Potdevin, F. J., Alberty, M. E., Chevutschi, A., Pelayo, P., and Sidney, M. C. (2011). Effects of a 6-week plyometric training program on performances in pubescent swimmers. J. Strength Cond. Res. 25, 80-86. doi: 10.1519/JSC.0b013e318 1 fef720

Prieske, O., Muehlbauer, T., Borde, R., Gube, M., Bruhn, S., Behm, D. G., et al. (2016). Neuromuscular and athletic performance following core strength training in elite youth soccer: Role of instability. Scand. J. Med. Sci. Sports 26, 48-56. doi: 10.1111/sms.12403

Ramírez-Campillo, R., Andrade, D. C., and Izquierdo, M. (2013). Effects of plyometric training volume and training surface on explosive strength. J. Strength Cond. Res. 27, 2714-2722. doi: 10.1519/JSC.0b013e318 $280 \mathrm{c} 9 \mathrm{e} 9$

Ramirez-Campillo, R., Andrade, D. C., Alvarez, C., Henríquez-Olguín, C., Martínez, C., Báez-Sanmartín, E., et al. (2014a). The effects of interset rest on adaptation to 7 weeks of explosive training in young soccer players. J. Sports Sci. Med. 13, 287-296.

Ramírez-Campillo, R., Meylan, C., Alvarez, C., Henríquez-Olguín, C., Martínez, C., Cañas-Jamett, R., et al. (2014b). Effects of in-season lowvolume high-intensity plyometric training on explosive actions and endurance of young soccer players. J. Strength Cond. Res. 28, 1335-1342. doi: $10.1519 /$ JSC. 0000000000000284

Ramírez-Campillo, R., Gallardo, F., Henriquez-Olguín, C., Meylan, C. M., Martínez, C., Álvarez, C., et al. (2015a). Effect of vertical, horizontal, and combined plyometric training on explosive, balance, and endurance performance of young soccer players. J. Strength Cond. Res. 29, 1784-1795. doi: 10.1519/JSC.0000000000000827

Ramírez-Campillo, R., Henríquez-Olguín, C., Burgos, C., Andrade, D. C., Zapata, D., Martínez, C., et al. (2015b). Effect of progressive volumebased overload during plyometric training on explosive and endurance performance in young soccer players. J. Strength Cond. Res. 29, 1884-1893. doi: $10.1519 /$ JSC. 0000000000000836

Ramírez-Campillo, R., Meylan, C. M., Álvarez-Lepín, C., Henriquez-Olguín, C. Martinez, C., Andrade, D. C., et al. (2015c). The effects of interday rest on adaptation to 6 weeks of plyometric training in young soccer players. J. Strength Cond. Res. 29, 972-979. doi: 10.1519/JSC.0000000000000283

Ramírez-Campillo, R., Burgos, C. H., Henríquez-Olguín, C., Andrade, D. C., Martínez, C., Álvarez, C., et al. (2015d). Effect of unilateral, bilateral, and combined plyometric training on explosive and endurance performance of young soccer players. J. Strength Cond. Res. 29, 1317-1328. doi: $10.1519 /$ JSC. 0000000000000762

Reeves, N. P., Narendra, K. S., and Cholewicki, J. (2007). Spine stability: the six blind men and the elephant. Clin. Biomech. 22, 266-274. doi: 10.1016/j.clinbiomech.2006.11.011

Rhea, M. R., Peterson, M. D., Lunt, K. T., and Ayllón, F. N. (2008). The effectiveness of resisted jump training on the VertiMax in high school athletes. J. Strength Cond. Res. 22, 731-734. doi: 10.1519/JSC.0b013e3181660c59

Richardson, C., Jull, G., Hodges, P., and Hides, J. (1999). Therapeutic Exercise for Spinal Segmental Stabilization in Low Back Pain: Scientific Basis and Clinical Approach. Edinburgh, NY: Churchill Livingstone.

Rivilla-Garcia, J., Martinez, I., Grande, I., and Sampedro-Molinuevo, J. (2011). Relationship between general throwing tests with a medicine ball and specific tests to evaluate throwing velocity with and without opposition in handball. $J$. Hum. Sport Exerc. 6, 414-426. doi: 10.4100/jhse.2011.62.22 
Roden, D., Lambson, R., and DeBeliso, M. (2014). The effects of a complex training protocol on vertical jump performance in male high school basketball players. J. Sports Sci. 2, 21-26.

Rubley, M. D., Haase, A. C., Holcomb, W. R., Girouard, T. J., and Tandy, R. D. (2011). The effect of plyometric training on power and kicking distance in female adolescent soccer players. J. Strength Cond. Res. 25, 129-134. doi: 10.1519/JSC.0b013e3181b94a3d

Ruiz, J. R., Castro-Piñero, J., España-Romero, V., Artero, E. G., Ortega, F. B., Cuenca, M. M., et al. (2011). Field-based fitness assessment in young people: the ALPHA health-related fitness test battery for children and adolescents. $\mathrm{Br}$. J. Sports Med. 45, 518-524. doi: 10.1136/bjsm.2010.075341

Saeterbakken, A. H., van den Tillaar, R., and Seiler, S. (2011). Effect of core stability training on throwing velocity in female handball players. J. Strength Cond. Res. 25, 712-718. doi: 10.1519/JSC.0b013e3181cc227e

Sáez de Villarreal, E., Suarez-Arrones, L., Requena, B., Haff, G. G., and Ferrete, C. (2015). Effects of plyometric and sprint training on physical and technical skill performance in adolescent soccer players. J. Strength Cond. Res. 29, 1894-1903. doi: 10.1519/JSC.0000000000000838

Sander, A., Keiner, M., Wirth, K., and Schmidtbleicher, D. (2013). Influence of a 2year strength training programme on power performance in elite youth soccer players. Eur. J. Sport Sci. 13, 445-451. doi: 10.1080/17461391.2012.742572

Sankey, S. P., Jones, P. A., and Bampouras, T. M. (2008). Effects of two plyometric training programmes of different intensity on vertical jump performance in high school athletes. Serb. J. Sports Sci. 2, 123-130.

Santos, E. J., and Janeira, M. A. (2008). Effects of complex training on explosive strength in adolescent male basketball players. J. Strength Cond. Res. 22, 903-909. doi: 10.1519/JSC.0b013e31816a59f2

Santos, E. J., and Janeira, M. A. (2009). Effects of reduced training and detraining on upper and lower body explosive strength in adolescent male basketball players. J. Strength Cond. Res. 23, 1737-1744. doi: 10.1519/JSC.0b013e3181b3dc9d

Santos, E. J., and Janeira, M. A. (2011). The effects of plyometric training followed by detraining and reduced training periods on explosive strength in adolescent male basketball players. J. Strength Cond. Res. 25, 441-452. doi: 10.1519/JSC.0b013e3181b62be3

Santos, E. J., and Janeira, M. A. (2012). The effects of resistance training on explosive strength indicators in adolescent basketball players. J. Strength Cond. Res. 26, 2641-2647. doi: 10.1519/JSC.0b013e31823f8dd4

Sheppard, J. M., Young, W. B., Doyle, T. L., Sheppard, T. A., and Newton, R. U. (2006). An evaluation of a new test of reactive agility and its relationship to sprint speed and change of direction speed. J. Sci. Med. Sport 9, 342-349. doi: 10.1016/j.jsams.2006.05.019

Siegler, J., Gaskill, S., and Ruby, B. (2003). Changes evaluated in soccerspecific power endurance either with or without a 10-week, in-season, intermittent, high-intensity training protocol. J. Strength Cond. Res. 17, 379-387. doi: 10.1519/1533-4287(2003)017<0379:CEISPE >2.0.CO;2

Silfies, S. P., Cholewicki, J., Reeves, N. P., and Greene, H. S. (2007). Lumbar position sense and the risk of low back injuries in college athletes: a prospective cohort study. BMC Musculoskelet. Disord. 8:129. doi: 10.1186/1471-2474-8-129

Soh, K. G., Ruby, H., and Soh, K. L. (2007). The impact of an eight-week aerobic and strength-training programme on agility and leg power of Malaysian netball players. J. Health Transl. Med. 10, 25-28.

Söhnlein, Q., Müller, E., and Stöggl, T. L. (2014). The effect of 16-week plyometric training on explosive actions in early to mid-puberty elite soccer players. J. Strength Cond. Res. 28, 2105-2114. doi: 10.1519/JSC.0000000000000387

Szymanski, D. J., McIntyre, J. S., Szymanski, J. M., Bradford, T. J., Schade, R. L., Madsen, N. H., et al. (2007a). Effect of torso rotational strength on angular hip, angular shoulder, and linear bat velocities of high school baseball players. $J$. Strength Cond. Res. 21, 1117-1125. doi: 10.1519/R-18255.1

Szymanski, D. J., Szymanski, J. M., Bradford, T. J., Schade, R. L., and Pascoe, D. D. (2007b). Effect of twelve weeks of medicine ball training on high school baseball players. J. Strength Cond. Res. 21, 894-901. doi: 10.1519/R-18415.1

Štefániková, G. (2013). Vplyv Rôznych Foriem Balančného Tréningu na Parametre Koordinačných Schopností Detí Mladšieho Školského Veku [The Effect of Different Forms of Balance Training on Coordination Abilities in Early School Age Children]. Ph.D. thesis.Comenius University in Bratislava, Faculty of Physical Education and Sport, Bratislava.
Tihanyi, J., Apor, P., and Fekete, G. (1982). Force-velocity-power characteristics and fiber composition in human knee extensor muscles. Eur. J. Appl. Physiol. 48, 331-343. doi: 10.1007/BF00430223

Thomas, K., French, D., and Hayes, P. R. (2009). The effect of two plyometric training techniques on muscular power and agility in youth soccer players. $J$. Strength Cond. Res. 23, 332-335. doi: 10.1519/JSC.0b013e318183a01a

Thompson, T., Berning, J., Harris, CH., Adams, K. J., and DeBeliso, M. (2017). The effects of complex training in male high school athletes on the back squat and vertical jump. Int. J. Sports Sci. 7, 50-55. doi: 10.5923/j.sports.20170702.05

Thorstensson, A., Grimby, G., and Karlsson, J. (1976). Force-velocity relations and fiber composition in human knee extensor muscles. J. Appl. Physiol. 40, 12-16. doi: $10.1152 /$ jappl.1976.40.1.12

Tsimahidis, K., Galazoulas, C., Skoufas, D., Papaiakovou, G., Bassa, E., Patikas, D., et al. (2010). The effect of sprinting after each set of heavy resistance training on the running speed and jumping performance of young basketball players. J. Strength Cond. Res. 24, 2102-2108. doi: 10.1519/JSC.0b013e3181e2eled

Tsolakis, C. K., Vagenas, G. K., and Dessypris, A. G. (2004). Strength adaptations and hormonal responses to resistance training and detraining in preadolescent males. J. Strength Cond. Res. 18, 625-629. doi: 10.1519/15334287(2004) $18<625$ :SAAHRT $>2.0$.CO;2

Wang, L. I., Lin, D. C., and Huang, C. (2004). Age effect on jumping techniques and lower limb stiffness during vertical jump. Res. Sports Med. 12, 209-219. doi: $10.1080 / 15438620490497549$

Weston, M., Hibbs, A. E., Thompson, K. G., and Spears, I. R. (2015). Isolated core training improves sprint performance in national-level junior swimmers. Int. J. Sports Physiol. Perform. 10, 204-210. doi: 10.1123/ijspp.2013-0488

Whitney, S. L., Roche, J. L., Merchetti, G. F., Lin, C. C., Steed, D. P., Furman, G. R., et al. (2011). A comparison of accelerometry and center of pressure measures during computerized dynamic posturography: a measure of balance. Gait Posture 33, 594-599. doi: 10.1016/j.gaitpost.2011. 01.015

Wong, P. L., Chamari, K., and Wisløff, U. (2010). Effects of 12-week onfield combined strength and power training on physical performance among U-14 young soccer players. J. Strength Cond. Res. 24, 644-652. doi: 10.1519/JSC.0b013e3181ad3349

Zagyi, P. (2010). Posudzovanie Rýchlosti Reakcie pri Kopoch v Športových Úpoloch Testom K-Reaction [The Assessment of Reaction Time of the Kick Using KReaction Test in Martial Arts]. Ph.D. thesis. Comenius University in Bratislava, Faculty of Physical Education and Sport, Bratislava.

Zemková, E., and Dzurenková, D. (2004). Functional diagnostics of karate athletes. KinSi. 10, 57-70.

Zemková, E. (2010). "Sensorimotor exercises in sports training and rehabilitation," in Trends in Human Performance Research, eds M. J. Duncan and M. Lyons (New York, NY: Nova Science Publishers, Inc.), 79-117.

Zemková, E., and Hamar, D. (2010). The effect of 6-week combined agility-balance training on neuromuscular performance in basketball players. J. Sports Med. Phys. Fitness 50, 262-267.

Zemková, E., and Hamar, D. (2013). Assessment of agility performance under sport-specific conditions. AJESS 10, 47-60.

Zemková, E., Vilman, T., Kováćiková, Z., and Hamar, D. (2013). Reaction time in the Agility Test under simulated competitive and non-competitive conditions. J. Strength Cond. Res. 27, 3445-3449. doi: 10.1519/JSC.0b013e3182903222

Zemková, E. (2014). Sport-specific balance. Sports Med. 44, 579-590. doi: 10.1007/s40279-013-0130-1

Zemková, E., and Hamar, D. (2014a). Age-related changes in agility time in children and adolescents. IJSR 3, 280-285.

Zemková, E., and Hamar, D. (2014b). Agility performance in athletes of different sport specializations. Acta Univ. Palacki. Olomouc. Gymn. 44, 133-140. doi: $10.5507 /$ ag.2014.013

Zemková, E., and Hamar, D. (2014c). Physiological mechanisms of post-exercise balance impairment. Sports Med. 44, 437-448. doi: 10.1007/s40279-013-0129-7

Zemková, E., Jeleň, M., Kováčiková, Z., Ollé, G., Vilman, T., and Hamar, D. (2014). Enhancement of peak and mean power in concentric phase of resistance exercises. J. Strength Cond. Res. 28, 2919-2926. doi: 10.1519/JSC.0000000000000517

Zemková, E. (2015). Functional performance testing across the lifespan. MR Int. J. Appl. Health Sci. 2, 26-41. 
Zemková, E., Jeleň, M., Kováčiková, Z., Ollé, G., Vilman, T., and Hamar, D. (2015a). Reliability and methodological issues of power assessment during chest presses on unstable surface with different weights. J. Sports Med. Phys. Fitness $55,922-930$.

Zemková, E., Miklovič, P., Dunajč́í, A., and Hamar, D. (2015b). Power as a parameter in the functional assessment of knee flexions and knee extensions on weight stack machines. Measurement 61, 141-149. doi: 10.1016/j.measurement. 2014.10.049

Zemková, E. (2016a). Agility Index as a measurement tool based on stimuli number and traveling distances. J. Strength Cond. Res. 31, 2141-2146. doi: $10.1519 /$ JSC. 0000000000001647

Zemková, E. (2016b). Differential contribution of reaction time and movement velocity to the agility performance reflects sport-specific demands. Hum. Mov. 17, 94-101. doi: 10.1515/humo-2016-0013

Zemková, E. (2016c). Instability resistance training for health and performance. J. Tradit. Complement. Med. 7, 245-250. doi: 10.1016/j.jtcme.2016.05.007

Zemková, E., Cepková, A., Uvaček, M., and Hamar, D. (2016a). A new method to assess the power performance during a lifting task in young adults. Measurement 91, 460-467. doi: 10.1016/j.measurement.2016. 05.077

Zemková, E., Kováčiková, Z., Jeleň, M., Neumannová, K., and Janura, M. (2016b). Postural and trunk responses to unexpected perturbations depend on the velocity and direction of platform motion. Physiol. Res. 65, 769-776.

Zemková, E., Štefániková, G., and Muyor, J. M. (2016c). Load release balance test under unstable conditions effectively discriminates between physically active and sedentary young adults. Hum. Mov. Sci. 48, 142-152. doi: 10.1016/j.humov.2016.05.002
Zemková, E., Cepková, A., Uvaček, M., and Šooš, L. (2017a). A novel method for assessing muscle power during the standing cable wood chop exercise. J. Strength Cond. Res. 31, 2246-2254. doi: 10.1519/JSC.0000000000001692

Zemková, E., Jeleň, M., Zapletalová, L., and Hamar, D. (2017b). Muscle power during standing and seated trunk rotations with different weights. Sport Mont. 15, 17-23. doi: 10.26773/smj.2017.10.003

Zemková, E., Vilman, T., Cepková, A., Uvaček, M., Olej, P., and Šimonek, J. (2017c). Enhancement of power in the concentric phase of the squat and jump: Between-athlete differences and sport-specific patterns. J. Hum. Sport Exerc. 12, 29-40. doi: 10.14198/jhse.2017.121.03

Zribi, A., Zouch, M., Chaari, H., Bouajina, E., Ben Nasr, H., Zaouali, M., et al. (2014). Short-term lower-body plyometric training improves whole body BMC, bone metabolic markers, and physical fitness in early pubertal male basketball players. Pediatr. Exerc. Sci. 26, 22-32. doi: 10.1123/pes.2013-0053

Conflict of Interest Statement: The authors declare that the research was conducted in the absence of any commercial or financial relationships that could be construed as a potential conflict of interest.

The reviewer HC and handling Editor declared their shared affiliation.

Copyright $\odot 2018$ Zemková and Hamar. This is an open-access article distributed under the terms of the Creative Commons Attribution License (CC BY). The use, distribution or reproduction in other forums is permitted, provided the original author(s) and the copyright owner are credited and that the original publication in this journal is cited, in accordance with accepted academic practice. No use, distribution or reproduction is permitted which does not comply with these terms. 